\title{
Tempo Effects and their Relevance in Demographic Analysis
}

\author{
Marc Luy
}

\begin{abstract}
Demographic period indicators like the total fertility rate or life expectancy are well known since more than a century and until recently there were only minor discussions about their usefulness. This changed with a series of publications by Bongaarts and Feeney (BF) in which they claimed that these indicators are inappropriate for describing current demographic conditions when the average age at childbearing respective death is changing. Therefore, BF proposed alternative tempo-adjusted indicators for such situations which can be very useful for demographic analysis. The still existing scepticism against the BF approach and the general rejection of mortality tempo adjustment in particular have their origin in a set of misunderstandings and misinterpretations of tempo-adjusted indicators. This paper systematically describes the basic idea of tempo effects, how they can distort the commonly used conventional period indicators and how the proposed methods approximate the idea of tempo adjustment, illustrated with empirical data for West Germany. We also summarize the critiques against tempo adjustment and try to put the tempo approach in the right perspective. Finally, the paper strives for providing a better understanding when tempo-adjusted measures should be used as alternative or in addition to the commonly used conventional demographic indicators.
\end{abstract}

Keywords: Tempo effects - Tempo adjustment - Tempo distortion - Bongaarts Feeney $\cdot$ Period analysis $\cdot$ Total fertility rate $\cdot$ Life expectancy

\section{Introduction}

Producing indices to summarize demographic conditions and to describe demographic trends is the main task of formal demography. Although demographers developed and are still developing a huge set of different indicators with very specific features most users of demographic data revert to a few specific indices only. In the field of fertility the most common indicator is the "total fertility rate" (TFR), usually known and interpreted as "average number of children per woman", and in the field of mortality it is "life expectancy" (LE) at birth or at an advanced age like 20 when 
one is interested in adult mortality only or at age 65 when the interest refers to the number of years of live in retirement.

These indicators are common and well known since more than a century and until recently there were only minor discussions about their usefulness. This changed, however, with a publication of Bongaarts and Feeney (1998) in which the authors claimed that the TFR is an inappropriate indicator for current fertility conditions when the average age at childbearing is changing and proposed an alternative indicator for such situations, the "tempo-adjusted" TFR* (with the asterisk symbolizing tempo-adjusted rates or indicators). Four years later, Bongaarts and Feeney (BF) extended their "tempo approach" to the analysis of mortality (Bongaarts/Feeney 2002), and another four years later they described a general framework of their approach that applies to any kind of demographic event (Bongaarts/Feeney 2006). Meanwhile tempo adjustment is widely practiced in the area of fertility analysis, whereas mortality tempo adjustment is less accepted and only used rarely in empirical analyses so far.

The different treatment of tempo adjustment among demographers in fertility and mortality is irrational since the basic idea behind the tempo approach is independent of the kind of demographic event. Same as the whole discussion surrounding the tempo approach the rejection of mortality tempo adjustment and the still existing scepticism against tempo adjustment among many scholars and users of demographic data are rooted in a set of misunderstandings and misinterpretations of tempo adjustment. This confusion was increased by the fact that in the first years after the initial BF publications the discussion focussed almost exclusively on technical aspects of the proposed tempo-adjusted indicators. Many demographers and users of demographic indices with different backgrounds did not or could not follow this complex technical discussion and as a consequence regarded tempo adjustment sceptically or repellent without understanding the tempo approach itself. The correct understanding of BF's basic idea is, however, very important for anyone who is interested in demographic conditions and processes.

Therefore, the aim of this paper is to systematically describe the basic idea of tempo effects, how they can distort the commonly used conventional demographic indicators and how the proposed methods approximate the idea of tempo adjustment. It is very important to note that the BF indicators are only approximations since a perfect statistical realization of tempo adjustment would require data in such detail that do not exist in empirical practice. The paper is mainly aimed for readers who never heard of tempo adjustment, heard a little bit about tempo adjustment or got confused in the complex discussion on tempo adjustment. However, the paper also contains some new thoughts and perspectives which might help changing the direction of the discussion among experts. We do not use any complex mathematical derivation or theoretical model in this paper but rather illustrate the aspects around tempo effects and tempo adjustment with empirical data for West Germany. Generally, in the German-speaking literature the tempo approach is only rarely picked out and we would also like to introduce this new demographic approach in this context. 
To get the right starting point when thinking about tempo effects and to avoid the common misunderstandings we begin with a short systematisation of the basic demographic concepts and indicators, like the substantial difference between period and cohort dimension (section 2). On this basis we describe the basic idea behind BF's tempo approach (section 3) and how it has to be seen in the period-cohort framework (section 4). In section 5 we compare the tempo-adjusted indicators with other alternative indices that are to some extent related to the BF indicators but differ from them conceptually. After separating tempo-adjusted indicators from these other concepts we summarize the critiques against BF's tempo approach in section 6 and try to put the tempo approach in the right perspective also admitting that some critical arguments are basically justified. However, as will be argued in this section of the paper, these aspects concern the technical realization of tempo adjustment and do not concern the basic idea itself. At the end we summarize the main aspects of the paper and combine them with the thoughts of other demographers who argued either in favour or against tempo adjustment. In conclusion we hope to provide a better understanding what tempo effects and tempo adjustment are and when they should be used as alternative or in addition to the commonly used conventional demographic indicators.

\section{Basic demographic concepts and indicators}

The most common demographic indicators like the TFR or LE are based on "demographic event rates". ${ }^{1}$ Demographic event rates are constructed by relating events (births, deaths, marriages, divorces, etc.) which occurred in a defined risk population (people of a specific cohort or people living at the same time with the same specific characteristics) to the risk years lived by the same population (with the same time reference). ${ }^{2}$ The TFR is based on age-specific fertility rates, i.e. the number of births by women aged $x$ divided by the risk years lived by women aged $x$. The TFR results from summing up these age-specific fertility rates over all reproductive ages (usually ages between 15 and 49 ). LE is based on age-specific death rates, i.e. the number of deaths of women or men aged $x$ divided by the corresponding risk

1 We use the term "demographic event rate" to avoid a separation between "rates of first kind" (which are also called "hazards" or "occurrence-exposure rates") and "rates of second kind" (which are also called "conditional rates" or "incidence rates") in order to keep the paper as simple as possible. In practice, rates of both kinds are used. Rates of first kind are used in mortality analysis where the denominator of the death rates (which includes all people living in a specific year or period) represents in fact the persons in risk of experiencing the event. Rates of second kind are typically used in fertility analysis. The denominator of age-specific fertility rates (which can be subdivided by parity) includes all women in reproductive ages, regardless whether they are at risk to experience a first birth, a second birth, etc. (for more details see Bongaarts/Feeney 2006). For most arguments presented in this paper the separation between rates of first and second kind is not necessary. However, rates of first and second kind exhibit different properties regarding tempo adjustment. We will come back to this issue in section 3 (footnote 8).

2 In empirical analysis, the risk years lived are usually approximated by the number of the average population (see e.g. Preston et al. 2001). 
Fig. 1: Cohort dimension in the Lexis diagram

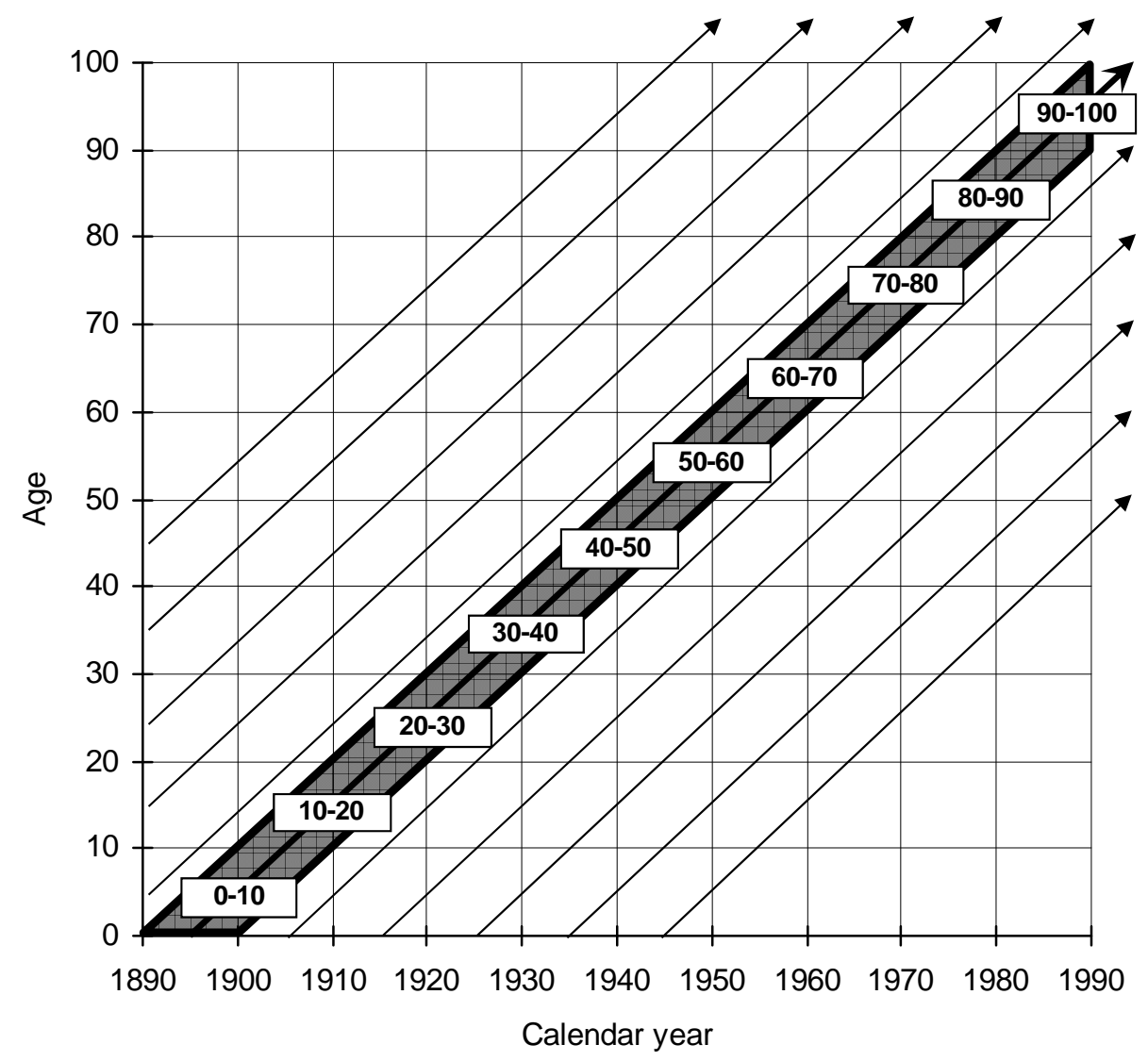

Source: own design

years lived, which are transferred into age-specific probabilities of dying. These probabilities of dying are combined to a survival function (life table) which enables us to derive LE.

Demographic indicators can be calculated for two different dimensions, namely the cohort and the period dimension. The calculation of the indicators, like the TFR or the LE, is identical for both dimensions. In the case of cohort indices the rates refer to specific birth cohorts, and in the case of period indices the rates refer to specific calendar years (or periods of more than one calendar year). Figures 1 and 2 illustrate the difference between cohort and period dimension in the Lexis diagram for a reference of ten birth year cohorts and for an observation time of ten calendar years, respectively. Calendar years are represented on the $x$-axes of the graphs and ages are represented on the $y$-axes. The diagonal lines through the diagram display processes of individual lifes, since with every additional calendar year an individual ages by one year of life (the arrows indicate the direction of time and ageing). In the 
Fig. 2: $\quad$ Period dimension in the Lexis diagram

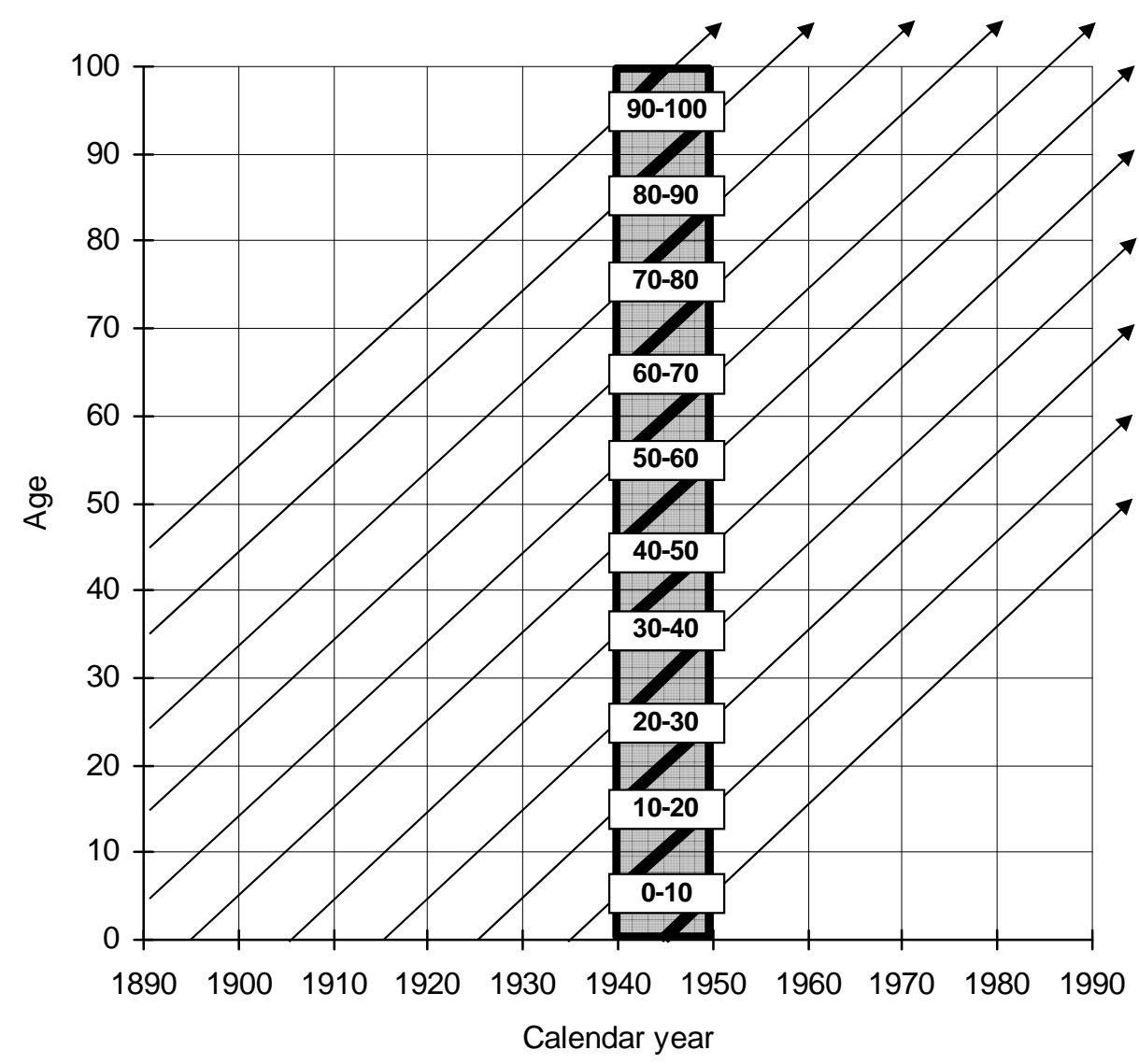

Source: own design

cohort dimension, all individuals born in a specific year (or period) are observed throughout their lives and demographic events and risk years are collected along the corresponding diagonals in the Lexis surface (dark-grey shaded diagonal area in Fig. 1, illustrated for the cohorts born between 1890 and 1900 and for 10-year age groups). The demographic event rates are calculated in the cohort dimension and combined to cohort summary indicators, like the cohort TFR (CTFR) or cohort life expectancy (CLE). Figure 2 illustrates the period dimension of demographic analysis. In the period perspective, all individuals living in a specific year (or period) are observed with regard to the risk years lived and demographic events experienced during this year (or period). The demographic event rates are calculated in the cross- 
sectional light-grey shaded area of the Lexis diagram and are combined to period summary indices, like the period TFR (PTFR) or period life expectancy (PLE). ${ }^{3}$

Many users of demographic indicators are not aware of the fundamental difference between cohort and period dimension. In most cases, people are interested in the experiences of cohorts. This already becomes evident when looking at the notations typically given to demographic indicators, like "average number of children per woman" or "life expectancy", which only have a clear meaning in the cohort dimension. The same indicators calculated for periods are very difficult to interpret and even demographers disagree in this respect. Basically all demographers however agree that period indicators are not representative for any real living individual. ${ }^{4}$ Nevertheless, most demographic indicators refer to periods. This is mainly due to the fact that only the period dimension provides a complete set of actual demographic event rates. Cohort indicators by their very nature refer to past events or they need to include a set of projected (not observed) rates for the future. Thus, the description of "current demographic conditions" and their year-to-year changes which are the most important kinds of information for the majority of users of demographic data can only be based on the period dimension.

The trials to define the meaning of demographic period indicators look very similar in all demographic and related publications. For instance, the statistical office of Germany defines the PTFR in the following way:

"The [period] total fertility rate gives the number of children a woman would have in her complete life if the conditions of the current year prevailed throughout her life from age 15 to 49 . The indicator has a hypothetical character, since it does not refer to a real but to a modelled cohort of women. Its advantages are that it provides actual information and measures the population's level of fertility independently of its age composition." (translated by the author from Statistisches Bundesamt 2009: 48; italics not in original)

3 Note that this paper does not deal with the general question whether the TFR and LE are the most suitable indicators for describing fertility and mortality. For example, Ní Bhrolcháin (1994) commented with respect to the analysis of fertility that "[i]n studying period fertility, we are concerned with the description and representation of change. There appears to be something profoundly contradictory in the convention of representing change (i.e. time trends in fertility) by an index [PTFR] which is interpreted through a hypothesis of unchanging fertility conditions. [...] [W]e should be sceptical about the validity of representing the fertility of a period in a metric which is inappropriate to the phenomena that occur in a period." (Ní Bhrolcháin 1994: 117). Ní Bhrolcháin's critiques against the PTFR do mainly concern the fact that changes in the population at risk by parity and duration since the last birth are not controlled for (see also $N i$ Bhrolcháin 1992). There are several alternative measures for period fertility, based on age-, duration- and parity-specific fertility data which might reflect fertility conditions more appropriate than the PTFR (see e.g., Rallu/Toulemon 1994).

4 The main problem is that period indicators are expressed in the same measurement units that only make sense for real cohorts. As stated by Ní Bhrolcháin with respect to fertility analysis, "[t]o use a mean family size as an indicator is to adopt a form of measurement that misrepresents what occurs in a period. Neither individual women nor the populations of which they are members acquire a mean number of children in a period" (Ní Bhrolcháin 1994: 117). 
Similarly, PLE is defined as:

"The average number of further years a person of a specific age can probably expect to live according to the current mortality conditions. It [PLE] is derived from the life table of the statistical office which is based on the actual probabilities of dying for the corresponding ages. It is a hypotheti$\mathrm{cal}$ measure since the mortality conditions might change during the course of the further life." (translated by the author from Statistisches Bundesamt 2009: 47-48; italics not in original)

The highlighted parts of these definitions represent the typical four features of conventional period indicators:

1. Period indicators are constructed to represent the demographic conditions prevailing in the current year or a period of years. Therefore, they include all events that occurred in the analyzed year or period.

2. Period indicators are given a clear interpretable meaning, like the "average number of children" in the case of the PTFR or the "average number of further years to live" in the case of PLE. These units of measurement fulfil one central function: they are easily understandable and interpretable, like a difference of one child per woman or ten years of life.

3. The populations to which period indicators refer are hypothetical, since it is quite clear that a real cohort of people will not experience current demographic event rates during their lives because demographic conditions usually change over time.

4. Since all demographic processes vary with age, the age composition of a population has a strong influence on the overall number of events that occur in a period. To allow the comparison of conditions of different populations or conditions in different times, period indicators are standardized for age.

In order to understand the basic idea behind tempo adjustment it is important to note that the BF approach is nothing more than an extension of the fourth feature of demographic period indicators. The other three features similarly apply to tempo-adjusted period indicators. Thus, BF's claim is simply to consider not only age but also tempo effects as a compositional factor which affects the total number of demographic events in a certain year or period, as will be described in the next section.

\section{The tempo approach of Bongaarts and Feeney}

In the logic of BF, the term "tempo effect" describes a change of period rates for demographic events (births, deaths, marriages, etc.) that solely results from a change of the average age at which the event occurs during the observation period. A tempo effect works as follows: an increase of the average age at occurrence leads to a decrease of period rates, and a decrease of the average age leads to an increase of period rates. Since demographic period rates are calculated with the aim of measuring the quantum of the analyzed event during the observation period in the sense of "current conditions" (i.e. the quantity of events in a specific year or period according 
to the demographic behaviour or experiences of the currently living individuals), tempo effects have to be seen as undesired distortions. ${ }^{5}$ Consequently, this holds equally for all demographic indicators derived from period rates, like the PTFR or PLE.

The basic intention of BF can be summarized as follows: In order to fulfil the central aim of demographic period indicators (i.e. the representation of demographic conditions prevailing in the current year or period of years; see feature 1 of conventional period indicators in the previous section), a standardization of age alone is not sufficient since tempo effects also cause distortions in period indicators. Therefore, period indicators should be standardized (adjusted) for tempo effects as well.

The justification for tempo adjustment is rooted in certain inconsistencies that might arise between demographic experiences of the real living population and those of a hypothetical population whose characteristics are based on conventional period rates. Such paradoxes have been demonstrated with very simple simulation models by Bongaarts and Feeney (1998) for the case of fertility and Bongaarts and Feeney (2002) for the case of mortality. The theoretical examples presented in these papers reveal that changing mean ages at which the demographic events occur can cause misleading information from period rates. For instance, it is possible that period fertility rates decline although fertility remains unchanged among all cohorts (Bongaarts/Feeney 1998) or that period mortality rates increase although all cohorts experienced only decreasing or stagnating mortality (Bongaarts/Feeney 2002; see also Horiuchi 2005 and Feeney 2010). Luy (2008, 2009) extended these models for demonstrating the consequences of tempo effects in period mortality by comparing two populations with different levels of mortality and different levels of mortality changes. He showed that it is possible that a population in which each cohort has higher mortality than the corresponding cohorts of another population can have lower period mortality rates when tempo effects are not adjusted for. Luy and Wegner (2009) further elaborated this example and demonstrated that such a situation can even occur with total life expectancy, i.e. that a population has a higher PLE than another population although the CLE of each cohort living in this period is lower in the population with higher PLE.

Luy $(2008,2009)$ and Luy and Wegner (2009) argued that such paradoxes contradict the main aim of period indicators which is to reflect current demographic conditions. The results of their simulations raise the following questions in favour of tempo-adjusted period indicators: Do we really want that PLE can indicate a lower mortality in a population in which each member dies earlier than in another population with lower PLE? Moreover, does anyone who uses period indicators for demographic conditions or processes and who interprets corresponding differences and trends take into account that such a paradoxical situation might occur?

5 That demographic period rates aim to measure the period quantum of the analyzed event is true for all kinds of period rates. For example, the age-specific fertility rate represents the average number of births of women in a certain age and the age-specific death rate represents the average number of deaths of women or men in a given age group. 
The possibility of contradictory results regarding differences in demographic conditions between populations in period and cohort perspective also has another very important consequence for the typical analysis of demographic processes. When we find differences in period conditions between populations (like a lower PTFR or PLE) we are usually trying to find the causes for these differences. Therefore, demographers (and scholars from other related disciplines) who want to explain such differences analyze the discrepancies between the studied populations with respect to the factors that are assumed to influence the level of fertility or mortality (or other demographic processes). However, such factors only apply to the real population and not to a hypothetical period population. The possibility that period conditions and trends can contradict the corresponding conditions and trends in the cohorts might cause severe problems for the analyzed cause-effects-chain since the real population living at a certain time consists of the members of different cohorts. Luy (2006) assumes such period distortions caused by tempo effects to be the reason why the trends in mortality differences between Eastern and Western Germany are still largely unexplained (see also Luy 2008, 2009).

Everyone who is aware of the specific features of period indicators is also aware of the fact that period indicators can differ from corresponding cohort indicators. For example, current PLE can (and probably will) be very different from the CLE of the current newborns, and the actual PTFR can differ from the average number of children of those cohorts who are currently within the reproductive life span. However, the analysis of period indicators can only be meaningful when they reflect the demographic experiences of the real population. The demographic conditions of cohorts should therefore be reflected by the combined period conditions of all years in which a cohort experienced demographic events. Empirical data reveals that this is not the case when conventional period indicators are summarized over the cohorts' life spans. For instance, West German women who were born in 1960 have a completed fertility of 1.60 children per woman (see Pötzsch 2010: 203). During the years from 1975 to 2009 , in which the women of the 1960 cohort reached the reproductive ages 15 to 49 , the PTFR ranged between 1.28 and 1.45 with an average PTFR of 1.38 .

Figure 3 shows the average number of children per woman of the West German birth cohorts from 1943 to 1961 according to the CTFR and according to reconstructions from weighted averages of the conventional PTFR and of the tempo-adjusted TFR ${ }^{*}{ }^{6}$ It becomes evident that the conventional PTFR does not allow reconstructing the real completed fertility. The reconstruction with the TFR*, however, resembles the real fertility conditions quite well. Similar examples can be given for the relation between CLE and the PLEs and LE*s of the 100 calendar years in which the cohorts lived their lives from birth to death (see Bongaarts/Feeney 2006).

6 The reconstructions of the CTFR were done in the following way. For example, women born in 1950 experienced their reproductive life span (approximately) in the years from 1965 to 2000 Thus, the reconstruction averaged the PTFRs and the TFR*s (separately for each birth order) for the years from 1965 to 2000 by weighting each of them with the proportion of the CTFR of the 1950 cohort that was realized in each calendar year (according to the corresponding agespecific fertility rates). 
Fig. 3: Average number of children per woman of the West German cohorts 1943 to 1961 according to the cohort total fertility rate (CTFR) and reconstructions from weighted averages of the PTFR and the TFR*

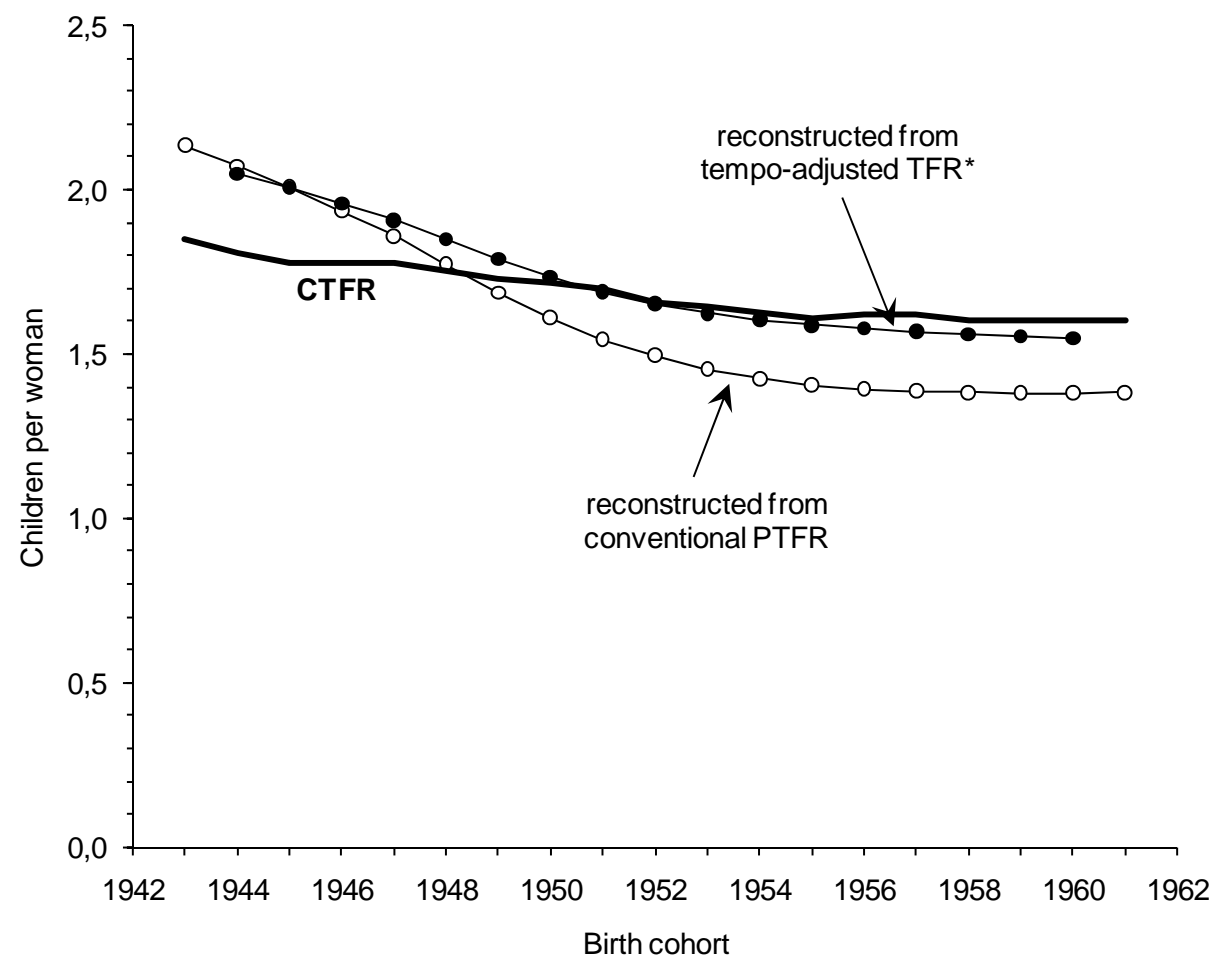

Source: own design; age-specific fertility rates by birth order were calculated by Luy and Pötzsch (2010 in CPoS 35,3)

These examples might help to understand the basic intention behind $\mathrm{BF}^{\prime}$ s tempo approach. Tempo adjustment, i.e. the standardization of period indicators for age and tempo effects, is supposed to provide period indicators which

1. allow a less distorted comparison of period conditions between populations or times, and

2. are closer to the average experience of real cohorts than conventional period indicators.

Because of (1), tempo-adjusted period measures are supposed to be more appropriate indicators for the demographic conditions prevailing in a specific year or period of years. Nevertheless, tempo-adjusted measures are also pure period indicators which refer to hypothetical cohorts same as conventional period indicators. Equivalently to what has been stated above for conventional period indicators, real cohorts will also not experience a given set of tempo-adjusted period rates during their lives. However, because of (2), the usual interpretations of period indicators, 
like "average number of children" or "average number of further years of life", are better fitting to tempo-adjusted indicators than to conventional ones.

In empirical applications of BF's tempo adjustment, conventional period rates (PR) have to be divided by one minus the annual change in the average age at which the corresponding event occurs during the period $p$ (denoted with $\left.r_{p}\right),{ }^{7}$ thus

$$
\mathrm{PR}^{*}=\frac{\mathrm{PR}}{1-\mathrm{r}_{\mathrm{p}}} .
$$

For age-specific rates like the age-specific fertility rates $f(x)$ or the age-specific death rates $M(x)$ these events are the births/deaths of mothers/women and men aged $x$. Thus, ideally, tempo adjustment of such age-specific rates would require knowledge about the shifts within the single ages (e.g. in age 32 from 32.3 to 32.4). ${ }^{8}$ Usually, however, single ages are the smallest unit of registration of demographic events and of the average population to approximate the risk years lived. Therefore, $\mathrm{BF}$ suggested to assume that the schedules of age-specific rates shift along the age axes without changing the shape as shown in Figures 4(a) and 4(b) for empirical sets of $f(x)$ and $M(x)$, respectively. Consequently, the annual change in the average age at childbearing/death derived from the whole schedules of age-specific fertility rates and age-specific death rates is assumed to apply to each single age. This implies that the BF model excludes specific cohort effects, or in other words, the BF model assumes that all cohorts respond identically to changing period conditions. Since in the case of mortality this "constant shape assumption" can be accepted to approximate reality only in developed populations, in more recent years and in ages above 30, the existing methods for mortality tempo adjustment proposed by $\mathrm{BF}$ (and thus their application) are limited to these restrictions. It is important to note that the assumptions of shifting age-specific fertility respective death rates with constant shape are approximate solutions only, but they allow the estimation of tempo-adjusted variants of period indicators like the PTFR and PLE.

The natural relation between period conditions and cohort experiences and BF's intention to provide period indicators that are closer to the average experience of

7 Bongaarts and Feeney (2006) refer to the term (1-r $p$ ) as "period distortion index".

8 Note that these age shifts refer to average ages at event occurrence derived from rates of second kind. In contrast to rates of first kind, rates of second kind are free of tempo distortions because the tempo distortion occurs in both the numerator and the denominator of the rates, and thus cancels out (see Bongaarts/Feeney 2006). This is why $r_{p}$ is derived differently for tempoadjustment of the TFR and LE. Whereas the typically used age-specific fertility rates are rates of second kind and thus the average age at childbearing derived from these rates can be directly used to estimate $r_{p}$, the typically used death rates (and measures derived from them like the conventional PLE) cannot be used for that purpose since these are rates of first kind (see footnote 1). Denominators of the death rates of second kind include all cohort members ever born i.e. persons who have already died as well as those who are still alive. Sardon $(1993,1994$ a) and Bongaarts and Feeney (2003) showed that these death rates of second kind can be regarded as comparable to the usual age-specific fertility rates and thus can be used to estimate the period distortion index $\left(1-r_{p}\right)$. 
Fig. 4: Bongaarts and Feeney's "constant shape assumption" to estimate ageinvariant changes in the average age at event occurrence

(a) Fertility

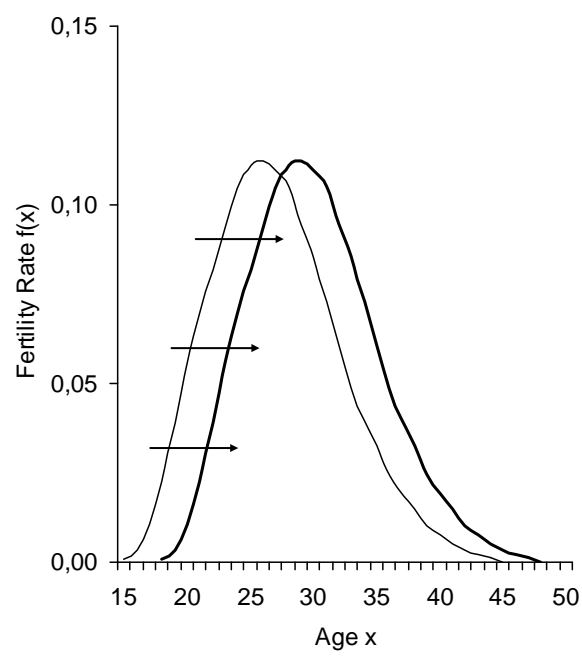

(b) Mortality

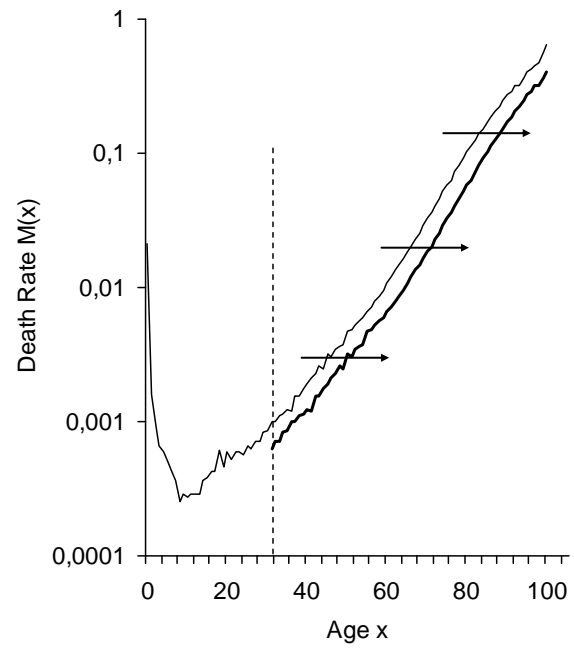

Source: own design

real cohorts than conventional period indicators caused several misunderstandings regarding the nature of tempo adjustment. Therefore it is helpful to separate tempoadjusted period indicators from other demographic measures which also connect period and cohort dimension.

\section{$4 \quad$ Classifying the tempo approach between period and cohort analysis}

In section 2 we introduced the basic demographic concepts of period and cohort analysis. There are several approaches that combine these two dimensions to produce demographic indices. Tempo-adjusted period indicators also include some but minor - cohort components as do other measures that combine the period and cohort dimension. In order to understand the basic idea behind the tempo approach and how it can be distinguished from other approaches it is necessary to separate between three methodological combinations of period and cohort analysis:

1. Translation measures,

2. Cross-sectional cohort averages,

3. Tempo-adjusted measures.

Translation measures aim to translate period indicators into cohort indicators and vice versa (see Fig. 5). Examples for translation measures are the approaches 
of Ryder (1964) or Zeng and Land (2002) for fertility analysis and the approaches of Schoen and Canudas-Romo (2005) as well as of Goldstein and Wachter (2006) for the analysis of mortality. The main characteristic of translation measures is that the outcomes are either cohort estimates derived from period rates or indicators, or period estimates derived from cohort rates or indicators. One of the translation approaches that operates in the direction from cohorts to periods results in the so-called "lagged cohort indices" like the "lagged cohort fertility rate" (LCFR) or the "lagged cohort life expectancy" (LCLE). The idea of lagged cohort indices is to use a cohort estimate, e.g. CTFR or CLE, as indicator for the demographic conditions in the period in which a cohort realized a demographic event on average. For instance, the cohort of West German women born in 1943 experienced a CTFR of 1.85 (children per woman) with an average age at childbearing of 26.5 years. In the lagged cohort approach, this CTFR can be used to characterize the fertility conditions of West German women in the year of 1969, i.e. the year in which the women of

Fig. 5: The concept of translation measures in the Lexis diagram

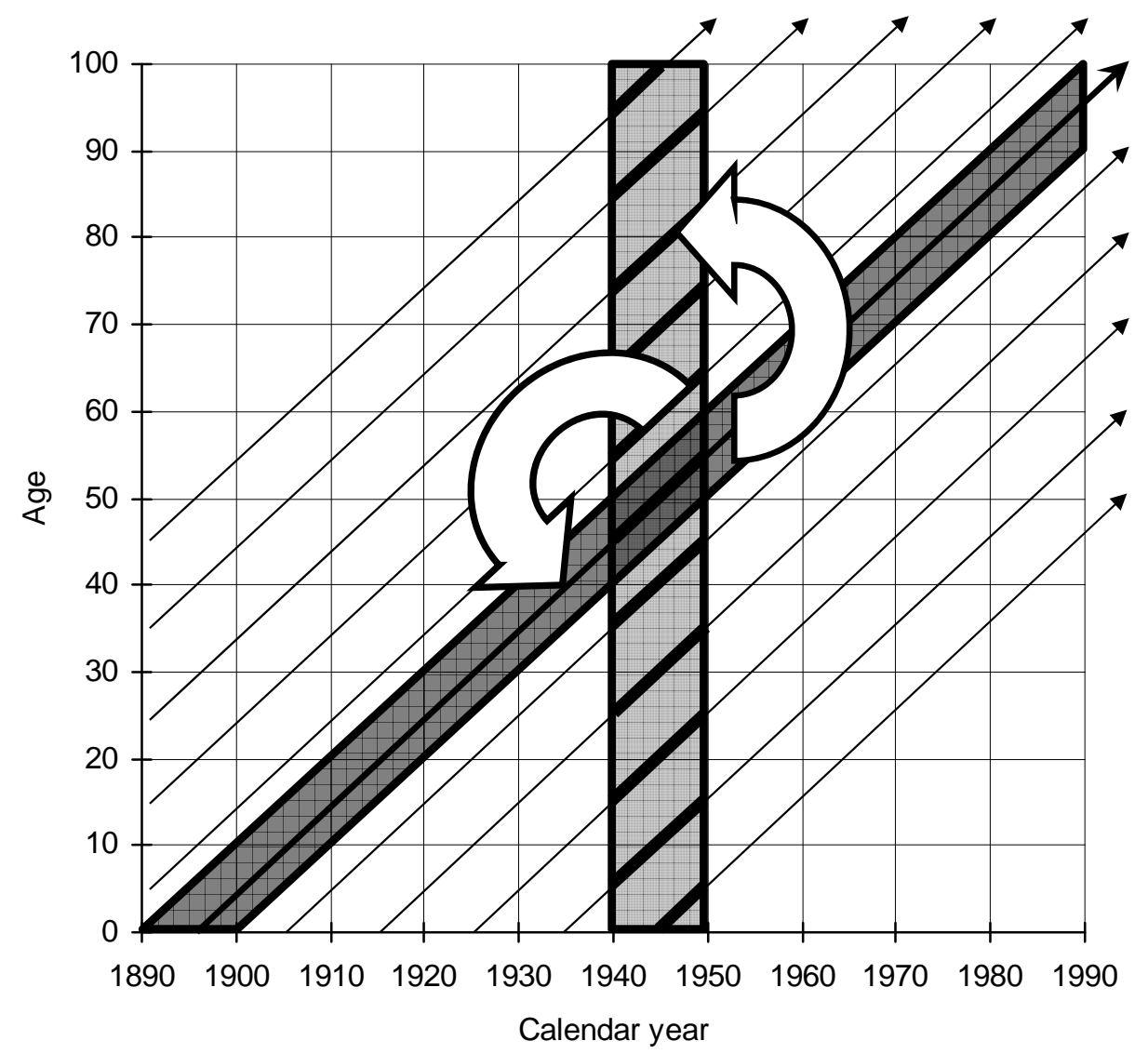

Source: own design 
the 1943 cohort realized their fertility on average $(1943+26.5=1969.5)$. Similarly, the CLE of a specific cohort can be used to characterize the mortality conditions of the calendar year that results from the year of birth of the cohort plus the average life expectancy of its members (i.e. the calendar year in which the members of the cohort died on average).

The main feature of cross-sectional cohort averages is that they produce a crosssectional average of the demographic experiences of all cohorts living in a specific period. The concept of cross-sectional cohort averages is illustrated in Figure 6 where the thick cohort arrows indicate that the complete lifetime experiences of all cohorts living in the light-grey shaded period are considered. In the field of fertility analysis, a cross-sectional cohort average is the "average completed fertility" (ACF) proposed by Ward and Butz (1980). The ACF is based on the so-called "timing index" (TI). Calculating the TI requires for each cohort living in the observation period the proportion of the overall CTFR that was realized during the analyzed calendar year(s). When fertility remains constant for all cohorts living in the observation period, the TI calculated as sum of these proportions will be 1.0. In the case of fertility postponement, the $\mathrm{TI}$ will be below 1.0, and in the case of advanced fertility, the $\mathrm{TI}$ will be higher than 1.0. As Schoen (2004) pointed out, "[t]he timing index measures the extent to which the cohort fertility of women childbearing during year $t$ occurs in year $t^{\prime \prime}$ (Schoen 2004: 806; italics in original). The ACF adjusts the PTFR for changes in the cohort timing of childbearing by dividing the PTFR with the TI. Thus, the "ACF does not reflect the fertility of any single cohort but represents a behaviourally weighted average of the fertility of all living cohorts" (Schoen 2004: 806). Obviously, this calculation can only be done for periods in the distinct past since the TI requires knowledge about the CTFR even for the youngest women alive in the observation period. A possibility to overcome this problem is to assume for all still reproductive cohorts the CTFR of the last cohort with completed fertility. This enables one to estimate the "ex-ante completed fertility" (ECF) even for the current period (see Ward/ Butz 1980). In our logic of classification the indices developed by Kohler and Ortega (2002a, 2002b) do also belong to the group of cross-sectional cohort averages since they also work in terms of real cohorts (see also van Imhoff 2001).

Cross-sectional cohort averages do also exist for the analysis of mortality, like the "total mortality rate" (TMR) as introduced by Sardon (1993, 1994a). As described by Guillot (2006: 4), "in a cohort (real or synthetic), the TMR is the number of lifetime deaths divided by the initial size of the cohort. In a life table with a radix of one, the TMR can be calculated by adding all age-specific life table deaths. Obviously, the TMR in a cohort, real or synthetic, is invariably one." However, the TMR can also be calculated cross-sectional for a specific period. Therefore it is necessary to determine the proportion of deaths occurring during the observation period for each cohort living within that period (adjusted for all migrations until the observation period), and by summing up these proportions across all cohorts (for more details, see Guillot 2006). In principle, the TMR can be seen as the mortality equivalent to the $\mathrm{Tl}$ reflecting the degree of completeness of the cross-sectional sum of cohort events. Like the TI in the case of fertility, the TMR equals 1.0 when mortality remains unchanged. As soon as some or all currently living cohorts experience a change in 
Fig. 6: The concept of cross-sectional cohort averages in the Lexis diagram

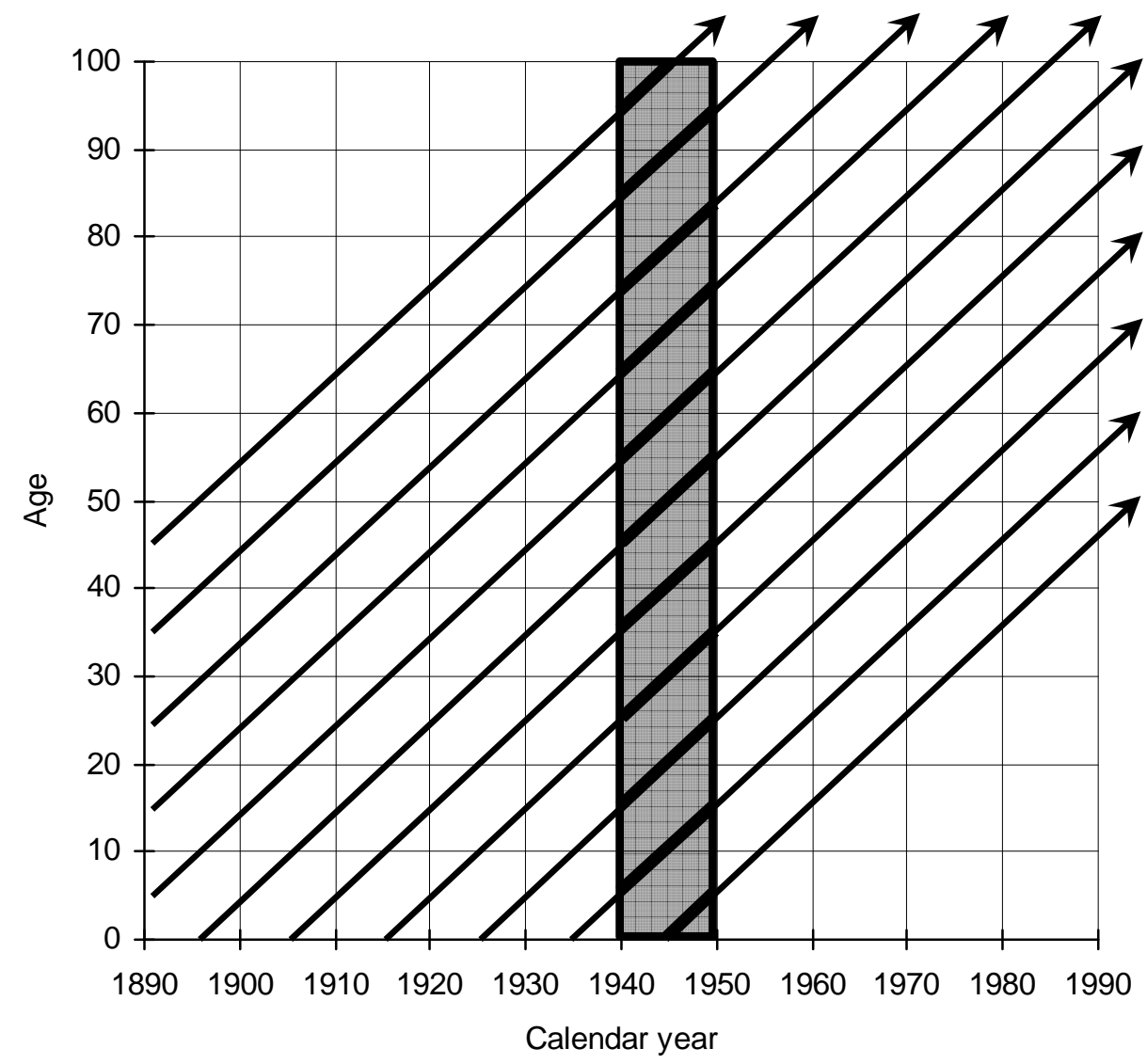

Source: own design

mortality conditions, the TMR changes as well and becomes higher than 1.0 in the case of increasing mortality and lower than 1.0 in the case of decreasing mortality (see also Luy/Wegner 2009). ${ }^{9}$

According to our classification of indices, another cross-sectional cohort average for period mortality is the "cross-sectional average length of life" (CAL) as introduced by Brouard (1986) and Guillot (2003). CAL is derived from the cross-sectional sum of the cohort-specific probabilities of surviving from birth to the age that the cohorts reach in the observation period (see also Guillot/Kim 2011). Since in the case of mortality the cohort quantum is always 1.0 , cross-sectional cohort averages

9 Additionally, the period TMR could also be regarded as mortality equivalent to the PTFR. Both represent the average number period events in a hypothetical cohort constructed on the basis of period- and age-specific indicators. 
like the TMR and CAL can be calculated even for the current period without the need to forecast the future quantum as it is the case with the $\mathrm{TI}$ and the ACF.

The TI and the TMR have the property that they directly reflect the occurrence of tempo effects in a specific period. Thus, the idea of cross-sectional cohort averages is to some extent related to BF's idea of tempo adjustment. The difference to tempo-adjusted measures is, however, that cross-sectional cohort averages are based on complete cohort experiences that are averaged for all events occurring in a specific period. As outlined in section 3 of this paper, tempo effects are solely based on the changes of the average age at event occurrence during the observation period. The cohorts' demographic experiences outside of the observation time do not matter in the logic of BF's tempo approach - at least theoretically - as illustrated in Figure 7. Tempo adjustment of period indices like the PTFR and PLE is performed on the basis of the annual change in the average age at childbearing and death, respectively, in the observation period only. Thus, tempo-adjusted measures

Fig. 7: The concept of tempo-adjusted measures in the Lexis diagram

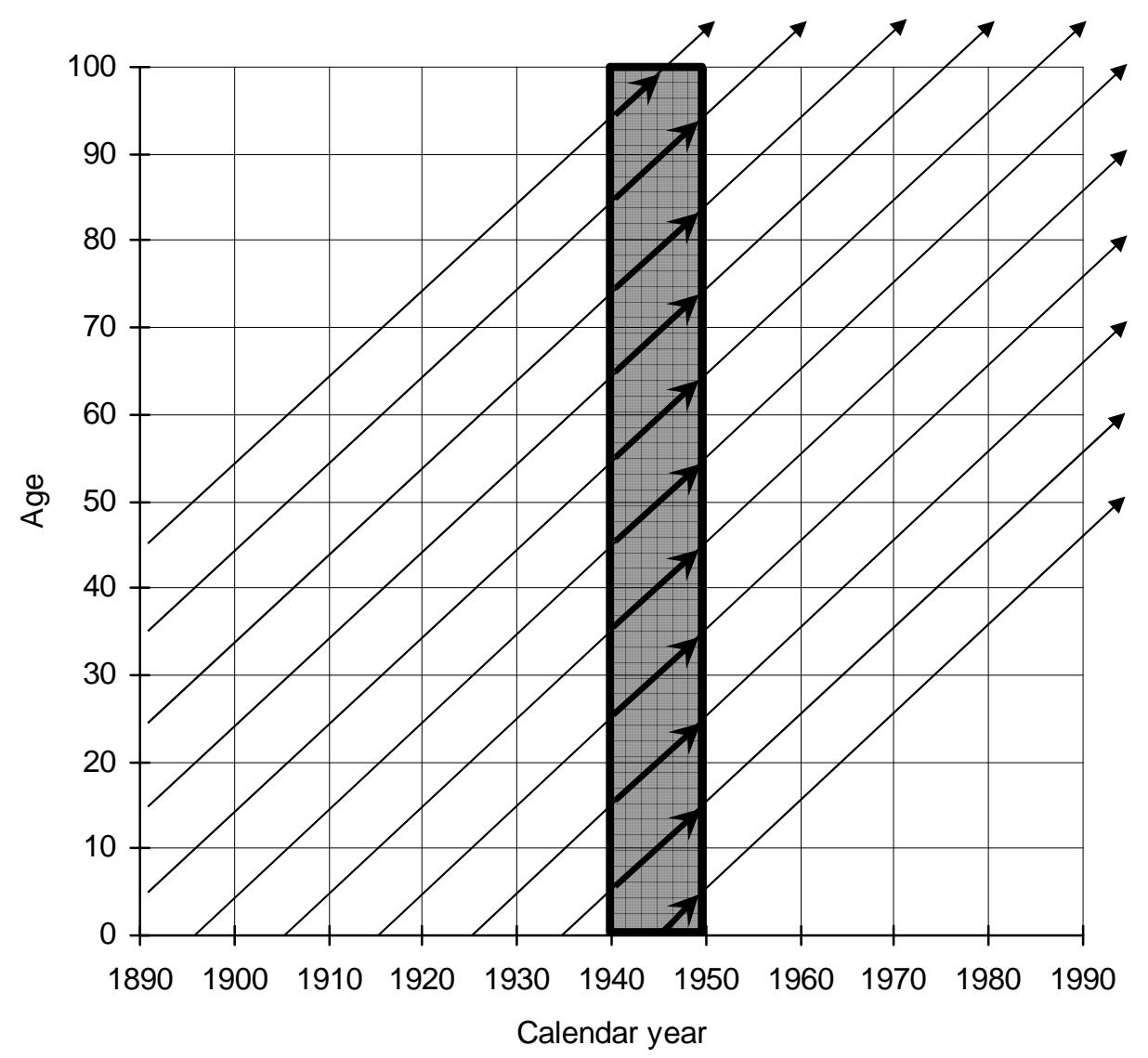

Source: own design 
are pure period indicators which adjust period quantum for period tempo (with period tempo being defined as the period-specific change in the timing of cohorts). Consequently, tempo-adjusted measures have to be separated conceptually from cross-sectional cohort averages. As will be shown in the subsequent section, ACF/ ECF and the tempo-adjusted TFR* are not only conceptually different but they also differ in empirical application.

\section{Translation measures, cross-sectional cohort averages and tempo- adjusted measures in empirical application}

The differences and familiarities between translation measures, cross-sectional cohort averages and tempo-adjusted measures can be demonstrated best by empirical data. Figure 8 shows the trends in the period total fertility rate (PTFR), the tempoadjusted fertility rate (TFR*), the ex-ante completed fertility (ECF) and the lagged cohort fertility rate (LCFR) for West Germany from 1960 to 2010. The LCFR displayed in the graph comprises the cohorts 1933 to 1961 which reached their average over-

Fig. 8: $\quad$ Period total fertility rate (PTFR), tempo-adjusted total fertility rate $\left(T F R^{*}\right)$, ex-ante completed fertility (ECF) and lagged cohort fertility rate (LCFR), West Germany, 1960-2010

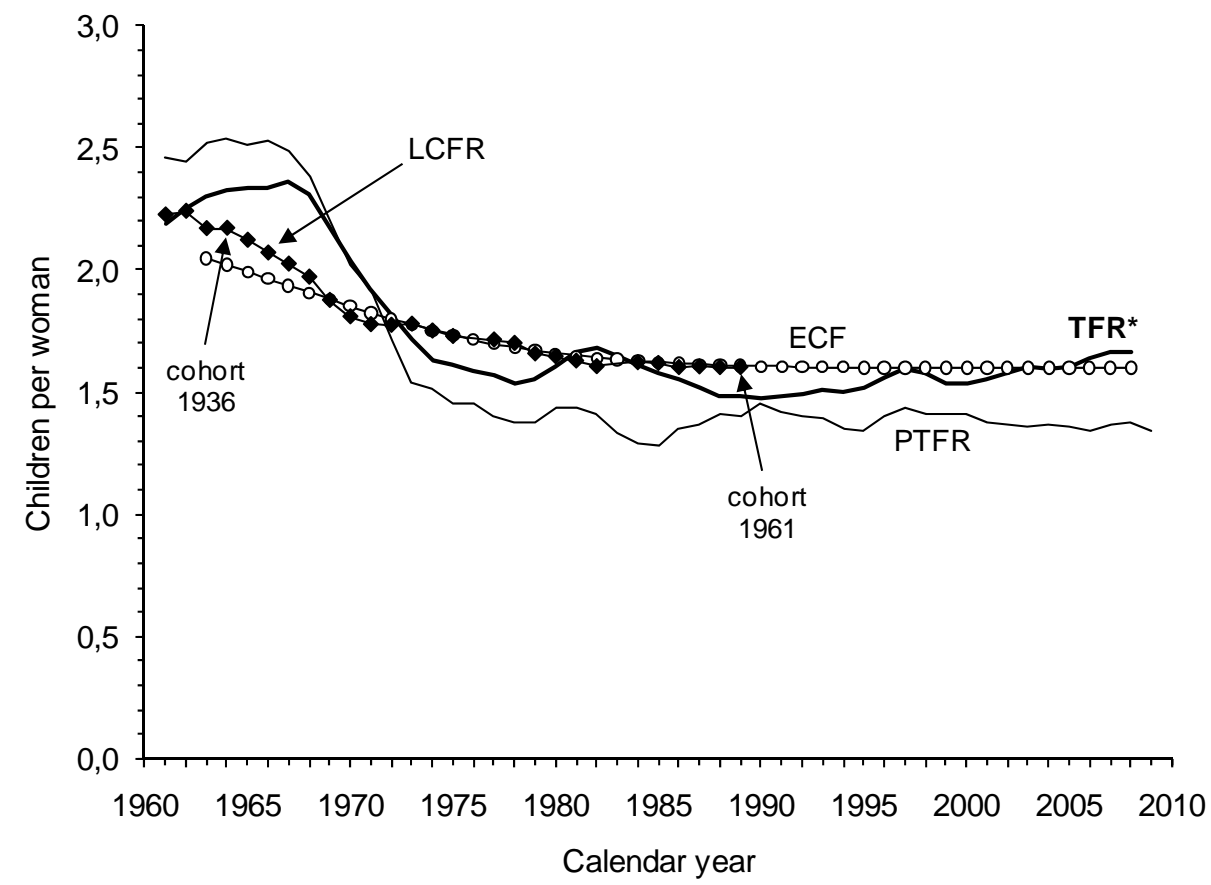

Source: PTFR and TFR* from Luy and Pötzsch (2010), ECF and LCFR based on own calculations; Note: calculations of ECF are based on the assumption that CTFR = 1.60 for cohorts born 1962 and later. 
all fertility in the years 1961 to 1989 . The ECF was calculated assuming that all still reproductive cohorts will have 1.60 children on average which is the CTFR for the cohort 1961 whose members reached the age of 48 in the last year for which data on age-specific fertility rates is available. Therefore, the ECF converts to the level of 1.60 children per woman in the most recent periods which equals the CTFR of the cohorts around 1960 and thus the LCFR of the late 1980s. However, also in the oldest periods displayed in Figure 8 the ECF is close to the LCFR with respect to both level and trend. This illustrates that the ECF as representative of the cross-sectional cohort averages is more related to cohort than to period indicators of fertility.

The PTFR as the most common indicator for period fertility shows a trend that is very different to the LCFR showing more fluctuations and different levels of fertility. Whereas the PTFR for West Germany is fluctuating around 1.37 since the mid-1970s, no cohort with completed fertility experienced less than 1.60 children on average. The trend of the TFR* is much closer to the trend of the PTFR than to the trend of ECF and LCFR. The level of the TFR*, however, is in most years closer to the LCFR and the ECF than to the conventional PTFR, especially since the 1970s when LCFR and PTFR became rather stable. This reveals that the tempo-adjusted TFR* is in fact an indicator of period fertility conditions, however, reflecting the fertility levels of the real cohorts rather than those of the hypothetical cohorts based on current agespecific fertility rates.

Figure 9 shows the trends of the different mortality indicators for West German males, i.e. conventional period life expectancy (PLE), tempo-adjusted life expectancy $\left(L^{*}\right)$, cross-sectional average length of life $(C A L)$ and lagged cohort life expectancy (LCLE). ${ }^{10}$ Similar to what has been shown for the fertility indicators, LE* is much closer to the life expectancy levels of CAL and LCLE indicating that the tempoadjusted period measure approximates the mortality experiences of the real population better than conventional PLE. It might seem puzzling that the tempo-adjusted $L^{*}$ is lower than the conventional PLE since it is well known that life expectancy is rising and thus PLE will be lower than the CLE of those being born in the current period. Note, however, that tempo-adjusted measures are not intended to project future CLE but to indicate the average mortality level experienced in the analysed calendar year by the currently living cohorts. From this perspective it makes sense that $L^{*}$ is smaller than PLE in a situation of decreasing mortality since tempo effects cause a downward bias of the age-specific death rates (see section 3 ). The similarity between $L^{*}$ and $C A L$ in the graph is primarily due to the fact that changes in life expectancy have been similar among periods and cohorts as can be seen in the trends of PLE and LCLE. Consequently, the tempo changes in period mortal-

${ }^{10}$ All indicators shown in Figure 9 assume no mortality under age 30 because the assumptions behind the BF model of mortality tempo adjustment hold only for ages 30 onwards (see section 3 of this paper). 
Fig. 9: Period life expectancy (PLE), tempo-adjusted life expectancy (LE*), cross-sectional average length of life (CAL) and lagged cohort life expectancy (LCLE) for men, West Germany, 1970-2010 (no mortality under age 30)

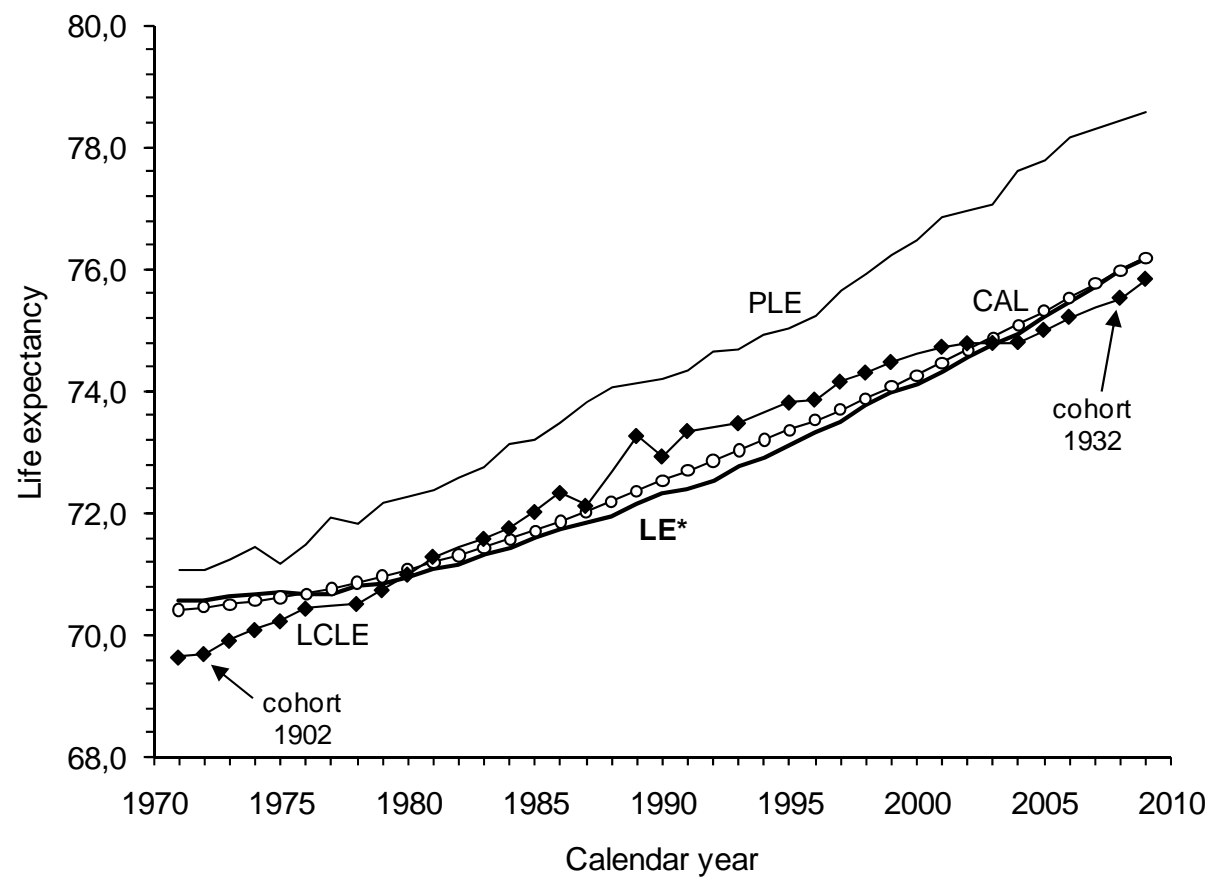

Source: own calculations; Notes: LE* was estimated with the TMR-method (see section 6); CAL and LCLE are based on estimates for CLE by Statistisches Bundesamt (2006) for total Germany with age-specific death rates being substituted by those for West Germany from 1950 onwards compiled by Luy (2004), updated until 2009.

ity are very similar to the corresponding changes in cohort mortality. ${ }^{11}$ This does, however, not mean that $\mathrm{LE}^{*}$ and $\mathrm{CAL}$ are conceptually identical. In corresponding estimates for populations for which available data allow to derive these indicators

11 The similarity between LCLE, CAL and LE* under specific theoretical and empirical conditions has also been shown by Bongaarts (2005), Bongaarts and Feeney (2006), Rodríguez (2006), Guillot (2006) and Guillot and Kim (2011). The closeness of LE* to LCLE and CAL is also partly due to the fact that the existing methods for mortality tempo adjustment include to some extent past trends of PLE (in the case of the indirect method suggested by Bongaarts/Feeney 2002) or cohort survival (in the case of methods using death rates of second kind). Thus, these different methods to estimate LE* combine characteristics of cross-sectional cohort averages and tempo-adjusted measures for period mortality. Note, however, that these are empirical approximations for $\mathrm{LE}^{*}$ which are only justified for contemporary populations from developed countries and from the age of 30 onwards. An exclusively period-based method to estimate LE* has not been developed yet. 
for a longer time period it becomes evident that $L^{*}$ and CAL differ in years with unstable and changing mortality conditions as shown by Bongaarts (2005) with data for Sweden.

\section{$6 \quad$ Critiques on Bongaarts' and Feeney's tempo approach}

The tempo approach of BF is subject to different kinds of criticism. However, most of the critiques are based on over-interpretations of tempo-adjusted period indicators. This makes it diffucult for demographic and non-demographic scholars to understand the basic approach behind tempo adjustment. Moreover, this situation causes restrictions on the empirical application of the tempo approach, especially with regard to mortality tempo adjustment. In this section we try to summarize the basic critiques and we try to evaluate them taking into account the basic idea behind the BF approach. Therefore, we describe the contents of these critiques rather than explicating them in detail. These details can be found in the given references or in summaries in van Imhoff (2001) and Schoen (2004) with regard to fertility tempo adjustment and in Barbi et al. (2008) with regard to mortality tempo adjustment.

The critiques in the field of fertility tempo adjustment can be summarized to four main arguments:

1. The tempo-adjusted TFR* is an inappropriate indicator for cohort fertility,

2. Cohort-specific changes in the timing of births are more complex in reality than assumed in the BF formula,

3. The tempo-adjusted TFR* does not take into account changes in the parity distributions of the female population,

4. The BF formula is based on inappropriate fertility measures.

From the point of view of BF's tempo approach one can reply quite easily to the first kind of critique, which was mainly brought up by van Imhoff (2001) and Schoen (2004): the tempo-adjusted TFR* is not supposed to be a cohort indicator of fertility. This also concerns the critique of Lesthaeghe and Willems (1999) who claimed that the $\mathrm{BF}$ model cannot be recommended to estimate prospective fertility rates. But also this is not the intention of tempo adjustment. The tempo-adjusted TFR* is nothing more than a standardized indicator for period fertility. The misunderstanding might be rooted in the original publication of Bongaarts and Feeney (1998) where the authors reconstructed cohort fertility from averaged PTFRs and TFR*s (as we did in section 3) to demonstrate that the averaged TFR* is closer to real cohort fertility than the averaged conventional PTFR. These averages were, however, neither conceptually nor technically constructed to reflect the fertility of real cohorts.

The second critique refers to the "constant shape assumption" in the BF model, which assumes that the shape of the order-specific age pattern of the age-specific fertility rates remains constant during the year of observation and thus the changes in the mean age at childbearing are due to shifts of the complete schedule of agespecific fertility rates (see section 3 of this paper). This aspect has been raised in 
several papers (van Imhoff/Keilman 2000; Kim/Schoen 2000; Inaba 2003; Keilman 2006; Schoen 2006) and it might in fact become problematic in cases where the variation in the mean age at childbearing is caused by severe changes in the age variance of the age-specific fertility rates. For instance, van Imhoff and Keilman (2000) showed that the constant shape assumption does not hold in empirical data for the Netherlands and Norway. However, Kohler and Philipov (2001) demonstrated that it is possible to extend the $\mathrm{BF}$ model to incorporate changes in the variance of the distribution of age-specific fertility rates if the necessary empirical data are available. More importantly, with respect to these alternative indicators for tempoadjusted period fertility Kohler and Philipov concluded that "[t]hese extensions [...] still support the necessity for adjusting the total fertility rate and related period fertility measures for tempo distortions in order to properly assess the quantum of fertility in many low-fertility settings" (Koh/er/Philipov 2001: 13). Also Zeng and Land (2001) introduced an extension of the simple BF adjustment. Their variant of the $\mathrm{TFR}^{*}$ allows the shape of the fertility schedule to change at a constant annual rate. They showed that the results of the methods are very similar implicating that tempo adjustment is quite insensitive to the constant shape assumption. An alternative approach to overcome the constant shape assumption was introduced by Kohler and Ortega (2002b) who suggested extending tempo adjustment to occurrence/exposure rates and parity progression ratios. However, this method combines properties of timing-and tempo-adjusted measures as described in section 4 of this paper.

The related third critique accuses the simple BF procedure of not taking changes in the parity distributions of the female population into account (van Imhoff/Keilman 2000; Kohler/Ortega 2002b). To address this issue, Bongaarts and Feeney (2006) have proposed an alternative of the basic BF method which was developed independently in a similar form by Yamaguchi and Beppu (2004). This tempo- and parityadjusted total fertility (TFRP*) is estimated by using age-specific birth hazard rates from fertility tables with all women who have not reached parity $\mathrm{i}-$ and not only those with i-1 births - being exposed to the risk of having an i-th birth. However, in empirical comparisons of the different methods the TFRP* and the simple TFR* provided very similar results, with Spain being the only exception (see Bongaarts/ Sobotka 2011). Moreover, the calculation of the TFRP* requires very detailed fertility data which does not exist for most countries including Germany.

The fourth argument, that was raised by van Imhoff and Keilman (2000) and Keilman (2006), concerns the way in which the order- and age-specific fertility rates are calculated in the BF model. The rates of the BF model are computed by dividing the number of births of a specific birth order of women aged $x$ by the total female population aged x. Keilman (2006: 219) claims that such rates in a period perspective introduce "extra tempo distortions" because summing up these rates for a specific parity implies the assumption that the proportion of women without children at the start of one age interval is equal to that proportion at the end of the previous age interval. This might in fact be a problem when these order- and age-specific fertility rates are used for demographic translation (see section 4 of this paper) or for analysing the risk of having a child of a specific birth order. However, in the BF model these rates are only used for decomposing the overall TFR into its order-specific 
components (see also Luy/Pötzsch 2010). In this respect, tempo-adjusted TFR* and conventional PTFR are identical since both can be decomposed into this kind of order-specific components. Thus, if this aspect is seen critical, the same argument must be used equivalently against the conventional PTFR. The decomposition of the age-specific fertility rates into their birth order components is necessary for tempo adjustment since the average age at childbearing of the birth orders might change in different directions, and thus order-specific tempo adjustment excludes an overall adjustment in the wrong direction.

Figure 10 shows that such a situation can indeed occur in empirical data. The graph depicts the average age at childbearing for the birth orders 1, 2, 3 and $4+$ as well as for all births combined (thick solid line) of West German women between 1960 and 2010. During the first half of the 1970s, the average age at childbearing was slightly decreasing, whereas the average ages at childbearing of birth orders 1 and 2 increased and those of birth order 3 and $4+$ decreased. Since births of first and second children have a much higher weight among all births than births of third children and children of higher birth orders (see Luy/Pötzsch 2010), a consideration of changes in the average age at childbearing for all births can lead to severe deficiencies in the tempo adjustment in such situations.

Mortality tempo adjustment is less accepted than fertility tempo adjustment until today and has been criticized in a number of papers. The contents of these papers can be summarized in two basic critiques:

1. Tempo-adjusted life expectancy is not a suitable measure for cohort life expectancy,

2. Mortality tempo adjustment is paradox since life expectancy is a tempo measure itself and the quantum of mortality is always one by definition.

The first argument of the critique against mortality tempo adjustment has been used for instance by Goldstein (2006) and can be returned equivalently as the first critique against fertility tempo adjustment: tempo-adjusted LE* is not supposed to reflect cohort life expectancy. The tempo-adjusted LE* is nothing more than a standardized indicator for period mortality. Further expectations towards this indicator would be over-interpretations of the BF model.

The second argument outlined by Wachter (2005), Wilmoth (2005) and Rodríguez (2006) seems convincing, but it is based on further misunderstandings which might be rooted in the two original publications of Bongaarts and Feeney $(1998,2002)$. Since the 1998 publication entitled "On the quantum and tempo of fertility" the idea of tempo adjustment seems firmly connected to the idea of quantum adjustment. Since tempo adjustment of life expectancy with the method proposed in Bongaarts and Feeney (2002) is done directly with the conventional PLE, the idea of quantum adjustment seems indeed paradox since the quantum of deaths in the life table (as the basis of PLE) is always one. The decisive aspect that is overseen in this critique is that tempo effects in the logic of BF do not have their origin in the life table but in the age-specific death rates which are based on the empirical deaths of the analyzed population. When age-specific death rates are affected by tempo effects, then the probabilities of dying, which are derived from the age-specific death rates, are 
Fig. 10: Average ages at childbearing for all births and by birth order in West Germany, 1960-2010

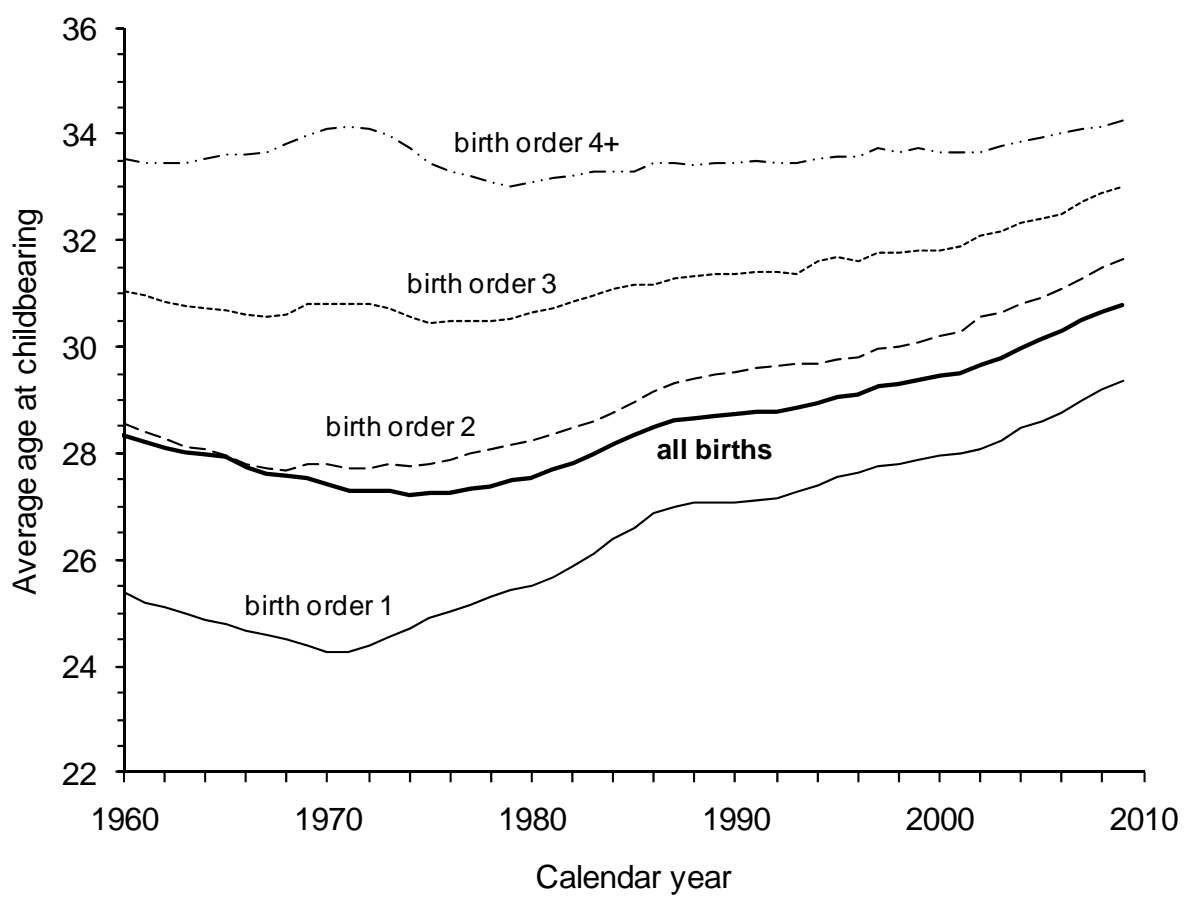

Source: own calculations with data from Luy and Pötzsch (2010)

affected by tempo effects, too. Consequently, the tempo effects are transported into the life table and affect all parameters derived from it. That the period TMR can lie distinctly below 1.0 as shown by Luy and Wegner (2009) with empirical data for West Germany reveals that empirical age-specific death rates are indeed affected by tempo effects. ${ }^{12}$

In principle, the critiques against tempo adjustment mix two fundamentally different questions:

1. Do tempo effects distort conventional period indicators?

2. Do BF's adjustment formulae provide adequate measures for tempo-adjusted period indicators?

12 The idea of tempo effects in the conventional PLE is more difficult to understand than the corresponding idea in the case of fertility analysis. In principal, the conventional period life table adjusts for tempo effects as well since it also produces a hypothetical population with TMR = 1.0. However, this "adjustment" is based on the age distribution of the empirical death rates and thus does not produce an adjustment in the sense of standardization because it differs between populations and periods (see Luy/Wegner 2009 for more details). 
In most papers criticizing the BF approach question (2) is answered with "no" and as a consequence, question (1) is answered in the same negative manner. This is illogical, especially because the existence of tempo effects in conventional period indicators has been described earlier by other authors without being criticised with regard to both fertility (Hajnal 1947) and mortality (Sardon 1994b). However, the two questions have to be separated in order to do justice to the BF approach. For instance, Wachter (2005) described in his rejection of mortality tempo adjustment that the tempo-adjusted LE* approximates a weighted average of past conventional PLEs. Regardless of the fact that the similarity between LE* and such a weighted average of past PLEs is in line with the BF approach as long as changes in life expectancy occur steadily (see section 5 of this paper), such an argument should not lead to the conclusion that mortality tempo adjustment itself is not justified. ${ }^{13}$ More detailed arguments opposing the critiques against mortality tempo adjustment can be found in Luy (2006) and Bongaarts and Feeney (2008).

In the meanwhile four different ways for estimating tempo-adjusted life expectancy have been suggested: (1) calculation of the "mean age at death" (MAD) based on death rates of second kind which directly provides a tempo effect-free measure for period life expectancy, ${ }_{14}$ (2) adjustment based on changes in "Gompertz' beta" (indirect method), (3) adjustment based on changes in CAL, and (4) adjustment based on the annual TMR (see Bongaarts/Feeney 2003 for more details). However, these methods are not based on different theoretical approaches. They are just different techniques to approximate the intended tempo adjustment. Figure 11 shows estimates for tempo-adjusted life expectancy in West Germany according to these different methodological approaches. The graph elucidates that the four methods are just alternative approaches to estimate tempo-adjusted life expectancy, in other words, to estimate the same thing.

There is no doubt that the existing methods for tempo adjustment in both fertility and mortality still have some deficiencies and further research should aim to improve these techniques. For instance, we should find a possibility to conduct tempo-adjustment age-specifically in order to relax the constant shape assumption. However, none of the critiques against the BF approach can be seen as a severe argument against the existence of tempo effects. The question is rather when and under which circumstances tempo-adjusted indicators should be used instead of or in addition to the conventional period indicators.

13 Wachter (2005) refers to the indirect method for estimating LE* proposed by Bongaarts and Feeney (2002). However, as outlined in footnote 11, this empirical solution for mortality tempo adjustment includes characteristics of both cross-sectional cohort averages and tempo-adjusted measures. Thus, Wachter's critique should refer to timing-adjusted measures for period mortality such as CAL as well. As soon as an exclusive period-based method for mortality tempo adjustment exists this critique does not hold anymore.

14 Note that MAD is not the mean age of deaths occurring in a specific calendar year since the effects of variations in cohort size (i.e. in the number of people alive in the single ages) are removed (see Bongaarts/Feeney 2006: 119). 
Fig. 11: Trends in LE* according to different methods of mortality tempo adjustment in comparison the tempo effect-free MAD, West Germany, 1970-2005

(a) Males

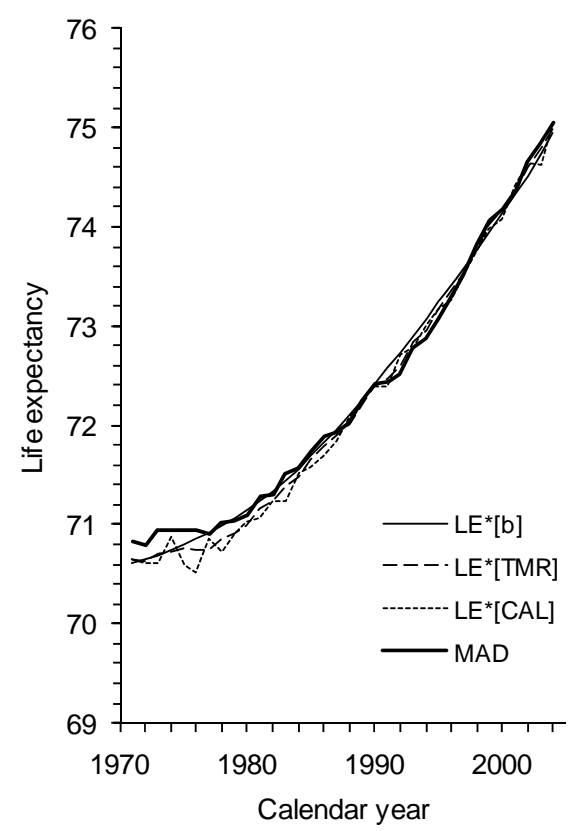

(b) Females

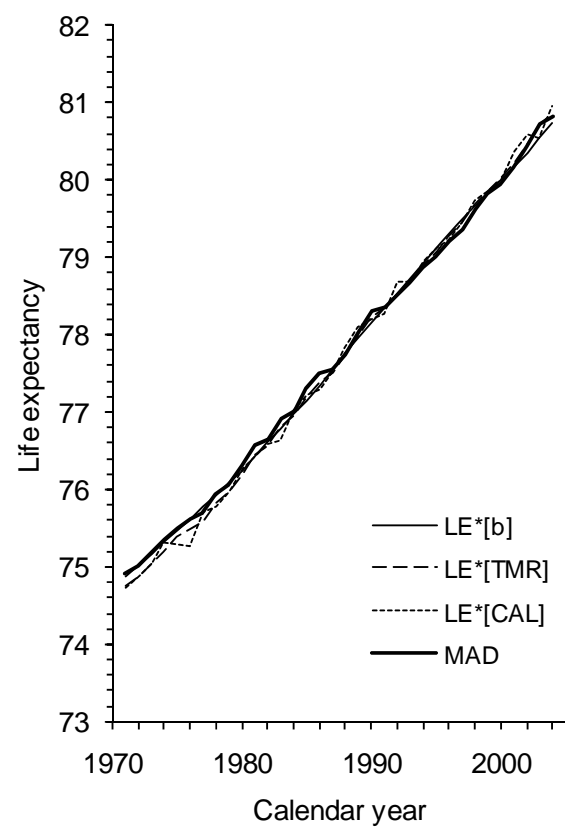

Source: own calculations; Notes: estimates for tempo-adjusted life expectancy are based on adjustments on basis of changes in "Gompertz' beta" (LE*[b]), changes in CAL $\left(\mathrm{LE}^{*}[\mathrm{CAL}]\right)$ and the annual TMR (LE* $\left.[\mathrm{TMR}]\right) ; \mathrm{MAD}=$ mean age at death based on death rates of second kind.

\section{Summary and conclusions}

We started this description of the idea behind BF's tempo approach with the basic difference between period and cohort perspective. This difference seems to be very clear at a first glance but it gets more complex the more intensive one deals with demographic indicators and their interpretation. As already stated by Calot (1994) in connection with fertility analysis, "[c]onceptually, the longitudinal perspective seems more natural, but the world we live in is essentially periodwise. [...] The tools of statistical observation used for cohort analysis are naturally the same as for period analysis. [...] But we prefer to synthesize period quantum independent/y of [...] specific population structures - which are, in a way, contingent - to obtain a result expressed, if possible, in cohort terms, closer to the individual. To do so, we concoct the fictitious cohort: we determine what the longitudinal measure would be for a cohort of women whose fertility performance at each different stage of 
their life course would be that of the period considered" (Calot 1994: 96-97, italics in original).

To understand BF's tempo approach correctly it is first of all important to realize that tempo-adjusted period indicators are by no means cohort but pure period measures to describe current demographic conditions. The conventional period indicators like the PTFR and PLE standardize for age as the only "specific population structure" in the words of Calot. However, a changing mean age at which the demographic events occur also causes additional structural effects that influence the quantitative outcome of the conventional period indicators. The main aim of tempo adjustment is to produce indicators that are free of the mix of quantum and tempo effects and estimate the tempo effect-free characteristics of demographic experiences. This tempo-quantum mix is evident in all kinds of demographic events and thus in all kinds of corresponding demographic event rates, including rates of fertility, mortality and other demographic processes. ${ }^{15}$

The indicators proposed by BF simulate a period situation in the absence of changing conditions which lead to changes in the age at occurrence. Conditions affecting fertility are, for example, level of education, women's labour force participation, availability of childcare facilities, government incentives and disincentives for childbearing, gender equality and cultural norms. Conditions affecting mortality are, among others, the availability and use of immunizations and other public health practices, the availability of medical devices, screening programs for early detection of different kinds of cancers, drugs that prolong life by reducing the incidence of particular life-threatening diseases, surgical procedures and behavioural changes that improve health and prolong life (see Bongaarts/Feeney 2010: 7). Thus, changing conditions are normal in human populations and this is why BF's tempo approach is relevant for everyone who is interested in the levels and trends of demographic processes in the period perspective.

The difference between conventional and tempo-adjusted period indicators is the theoretical model behind the hypothetical cohort that is constructed to represent the current demographic conditions. As stated by Keilman (1994: 112) for the analysis of fertility, "whatever fertility rate we compute [...], there is always an underlying model, and [...] computing the rate in fact boils down to estimating a parameter in that model." The decisive question for anyone interested in or using demographic indicators is which model is more appropriate, or in other words: conventional period indicators based on current demographic event rates versus tempo-adjusted period indicators based on BF's idea of unchanging conditions which tells us more?

This question can only be answered on basis of the purpose for which one uses a demographic period indicator. Since, as we have indicated, all period measures are hypothetical by their very nature, it is not possible to conclude that one model is

15 In this paper we concentrated exclusively on fertility and mortality. However, tempo effects have been described and analyzed also with regard to nuptiality (see Winkler-Dvorak/Engelhardt 2004 and Bongaarts/Feeney 2006) 
correct and the other is incorrect (see also Inaba 2007). But it is possible to estimate the consequences the models have for the parameter calculated and whether these consequences meet the purpose of its use. In most cases, the goal of period analysis is the representation of current demographic conditions with the aim to study time trends and to compare different populations. The paradoxes that might occur between demographic experiences of the real living population and those of a hypothetical population whose characteristics are based on conventional period rates (see section 3 of this paper) support the use of tempo-adjusted indicators for these purposes, at least in addition to the conventional period indicators (see also Sobotka/Lutz 2010). Conventional rates do not reflect real conditions that occurred in a population in years of changing conditions. Tempo-adjusted rates do, at least they do better. Cross-sectional cohort averages also reflect the real conditions, however, derived from the cohort perspective. Moreover, cross-sectional cohort averages for fertility have the problem that they can be calculated only for periods of more than 30 years in the past or that they need assumptions regarding the completed fertility of the currently reproductive cohorts. In this case they reflect more cohort projections than real current conditions.

It is true that it is also possible to use conventional period indicators and analyze them in the light of parallel changes in the age at event occurrence. Especially in the case of fertility analysis this seems to be a possible alternative to tempo adjustment. However, such an analysis requires deep demographic expertise to understand the relationships between the figures. Many users of demographic data do not have this specific background knowledge. Moreover, having one indicator that can be interpreted easily is much more useful for most users of demographic data. In mortality, the use of different indicators to interpret trends in conventional PLE would be even more difficult.

As already mentioned several times in this paper, the existing methods for tempo-adjustment are only approximations of the basic approach of BF and they are imperfect solutions in cases where the basic statistical assumptions behind the methods are not fulfilled. BF themselves wrote just recently: "Tempo effects can be measured, and appropriate corrections can be made, only by imposing simplifying assumptions. The most important of these in our analysis is that there are no cohort effects, i.e. all cohorts respond to changing period conditions in the same way. We have argued elsewhere that this assumption holds approximately for fertility and adult mortality in many contemporary populations. When this simplifying assumption does not hold, the [tempo-adjusted indicator] is affected by distortions other than tempo effects, e.g. a changing parity distribution in the case of fertility. In such cases tempo effects still exist, but the measurement of quantum and tempo becomes difficult. The conventional BF method for estimating tempo effects is then not accurate and it does not address these other distortions. Further methodological research is needed to develop general methods for estimating period quantum and tempo" (Bongaarts/Feeney 2010: 9-10).

The main aim of this paper was to describe the theoretical idea behind tempo adjustment and to separate the idea from the technical aspects of tempo adjustment. We also hope that the paper is helpful in order to evaluate the critiques against the 
tempo approach properly. In fact, most of the critiques are not related to the basic idea of BF. The tempo approach is straightforward and tempo-adjusted indicators like TFR* or LE*can be interpreted as the TFR/LE that would have been observed in year $t$ if the pattern of age-specific fertility rates (for each birth order)/death rates (i.e., shape and location at the age axes) had been constant during the whole year and only the values of the rates had been changed. Thus, tempo-adjusted indicators are based on the theoretical quantum of demographic events that would have occurred, if conditions and thus the average age of occurrence did not change during the year of observation. In most practical uses of demographic period indices, these criteria for standardization create indicators with useful information for its purpose. Conventional period indicators are simpler, but this simplicity implies a certain risk that important structural effects which are not standardized for distort the information one wants to get.

\section{References}

Barbi, Elisabetta; Bongaarts, John; Vaupel, James W. (Eds.) 2008: How long do we live? Demographic models and reflections on tempo effects. Demographic Research Monographs 5. Leipzig: Springer.

Bongaarts, John 2005: Five period measures of longevity. In: Demographic Research 13,21: 547-558 [doi:10.4054/DemRes.2005.13.21].

Bongaarts, John; Feeney, Griffith 1998: On the quantum and tempo of fertility. In: Population and Development Review 24,2: 271-291.

Bongaarts, John; Feeney, Griffith 2002: How long do we live? In: Population and Development Review 28,1: 13-29 [doi:10.1111/j.1728-4457.2002.00013.x].

Bongaarts, John; Feeney, Griffith 2003: Estimating mean lifetime. In: Proceedings of the National Academy of Sciences 100,23: 13127-13133 [doi:10.1073/pnas.2035060100].

Bongaarts, John; Feeney, Griffith 2006: The quantum and tempo of life-cycle events. In: Vienna Yearbook of Population Research 2006: 115-151 [doi:10.1553/populationyearbook2006s115].

Bongaarts, John; Feeney, Griffith 2008: Afterthoughts on the mortality tempo effect. In: Barbi, Elisabetta; Bongaarts, John; Vaupel, James W. (Eds.): How long do we live? Demographic models and reflections on tempo effects. Leipzig: Springer, 263-269.

Bongaarts, John; Feeney, Griffith 2010: When is a tempo effect a tempo distortion? In: Genus 66,2: 1-15.

Bongaarts, John; Sobotka, Tomáš 2011: Demographic explanations for the recent rise in Europe's fertility: analysis based on the tempo and parity adjusted total fertility rate. Paper presented at the Annual Meeting of the Population Association of America 2011. Washington, D.C.

Brouard, Nicolas 1986: Structure et dynamique des populations. La pyramide des années à vivre, aspects nationaux et examples régionaux. In: Espaces, Populations, Sociétés 2,14/15: 157-168.

Calot, Gérard 1994: Synthetic measures based on rates or on probabilities. In: Population: An English Selection 6: 95-107. 
Feeney, Griffith 2010: Mortality tempo: a guide for the skeptic. In: Comparative Population Studies - Zeitschrift für Bevölkerungswissenschaft 35,3: 483-496 [doi: 10.4232/10. CPoS-2010-12en].

Goldstein, Joshua R. 2006: Found in translation? A cohort perspective on tempoadjusted life expectancy. In: Demographic Research 14,5: 71-84 [doi:10.4054/ DemRes.2006.14.5].

Goldstein, Joshua R.; Wachter, Kenneth H. 2006: Relationships between period and cohort life expectancy: gaps and lags. In: Population Studies 60,3: 257-269 [doi:10.1080 /00324720600895876].

Guillot, Miche/ 2003: The cross-sectional average length of life (CAL): a cross-sectional mortality measure that reflects the experience of cohorts. In: Population Studies 57,1: 41-54 [doi:10.1080/0032472032000061712].

Guillot, Michel 2006: Tempo effects in mortality: an appraisal. In: Demographic Research 14,1: 1-26 [doi:10.4054/DemRes.2006.14.1].

Guillot, Michel; Kim, Hyun S. 2011: On the correspondence between CAL and lagged cohort life expectancy. In: Demographic Research 24,25: 611-632 [doi:10.4054/DemRes.2011.24.25].

Hajnal, John 1947: The analysis of birth statistics in the light of the recent international recovery of the birth-rate. In: Population Studies 1,2: 137-164.

Horiuchi, Shiro 2005: Tempo effect on age-specific death rates. In: Demographic Research 13,8: 189-200 [doi:10.4054/DemRes.2005.13.8].

Inaba, Hisashi 2003: Resolving a confusion in the Bongaarts and Feeney's tempo-adjusted total fertility rate. In: Jinkogaku Kenkyu (The Journal of Population Studies) 32: 1-7.

Inaba, Hisashi 2007: Effects of age shift on the tempo and quantum of nonrepeatable events. In: Mathematical Population Studies 14,3: 131-168 [doi: 10.1080/08898480701426225].

Keilman, Nico 1994: "Period fertility indicies" - a comment. In: Population: An English Selection 6: 111-115.

Keilman, Nico 2006: Demographic translation. From period to cohort perspective and back. In: Caselli, Graziella; Vallin, Jacques; Wunsch, Guillaume (Eds.): Demography: analysis and synthesis I. London: Academic Press: 215-225.

Kim, Young J.; Schoen, Robert 2000: On the quantum and tempo of fertility: limits to the Bongaarts-Feeney adjustment. In: Population and Development Review 26,3: 554-559 [doi:10.1111/j.1728-4457.2000.00554.x].

Kohler, Hans-Peter; Ortega, José A., 2002a: Tempo-adjusted period parity progression measures: assessing the implications of delayed childbearing for cohort fertility in Sweden, the Netherlands and Spain. In: Demographic Research 6,7: 145-190 [doi:10.4054/DemRes.2002.6.7].

Kohler, Hans-Peter; Ortega, José A. 2002b: Tempo-adjusted period parity progression measures, fertility postponement and completed cohort fertility. In: Demographic Research 6,6: 91-144 [doi:10.4054/DemRes.2002.6.6].

Kohler, Hans-Peter; Philipov, Dimiter 2001: Variance effects in the Bongaarts-Feeney formula. In: Demography 38,1: 1-16 [doi:10.1353/dem.2001.0004].

Lesthaeghe, Ron; Willems, Pau, 1999: Is low fertility a temporary phenomenon in the European Union? In: Population and Development Review 25,2: 211-228 [doi:10.1111/ j.1728-4457.1999.00211.x]. 
Luy, Marc 2004: Verschiedene Aspekte der Sterblichkeitsentwicklung in Deutschland von 1950 bis 2000. In: Zeitschrift für Bevölkerungswissenschaft 29,1: 3-62.

Luy, Marc 2006: Mortality tempo-adjustment: an empirical application. In: Demographic Research 15,21: 561-590 [doi:10.4054/DemRes.2006.15.21].

Luy, Marc 2008: Mortality tempo-adjustment: theoretical considerations and an empirical application. In: Barbi, Elisabetta; Bongaarts, John; Vaupel, James W. (Eds.): How long do we live? Demographic models and reflections on tempo effects. Leipzig: Springer: 203-233.

Luy, Marc 2009: Der Einfluss von Tempo-Effekten auf die ost-west-deutschen Unterschiede in der Lebenserwartung. In: Cassens, Insa; Luy, Marc; Scholz, Rembrandt D. (Eds.): Die Bevölkerung in Ost- und Westdeutschland. Demografische, gesellschaftliche und wirtschaftliche Entwicklungen seit der Wende. Wiesbaden: VS-Verlag für Sozialwissenschaften: 140-168.

Luy, Marc; Pötzsch, Olga 2010: Estimates of the tempo-adjusted total fertility rate in Western and Eastern Germany, 1955-2008. In: Comparative Population Studies Zeitschrift für Bevölkerungswissenschaft 35,3: 605-636 [doi: 10.4232/10.CPoS-201014en].

Luy, Marc; Wegner, Christian 2009: Conventional versus tempo-adjusted life expectancy - which is the more appropriate measure for period mortality? In: Genus 65,2: 1-28.

Ní Bhrolcháin, Máire 1992: Period paramount? A critique of the cohort approach to fertility. In: Population and Development Review 18,4: 599-629.

Ní Bhrolcháin, Maíre 1994: Past history, synthetic indicators and period fertility. In: Population: An English Selection 6: 116-120.

Pötzsch, Olga 2010: Cohort fertility: a comparison of the results of the official birth statistics and the Microcensus survey 2008. In: Comparative Population Studies - Zeitschrift für Bevölkerungswissenschaft 35,1: 185-204 [doi: 10.4232/10.CPoS-2010-05en].

Preston, Samuel H.; Heuveline, Patrick; Guillot, Michel 2001: Demography. Measuring and modeling population processes. Oxford: Blackwell.

Rallu, Jean-Louis; Toulemon, Laurent 1994: Period fertility measures. The construction of different indices and their application to France, 1946-89. In: Population: An English Selection 6: 59-93.

Rodríguez, Germán 2006: Demographic translation and tempo effects: an accelerated failure time perspective. In: Demographic Research 14,6: 85-110 [doi:10.4054/ DemRes.2006.14.6].

Ryder, Norman B. 1964: The process of demographic translation. In: Demography 1,1: 74-82.

Sardon, Jean-Paul 1993: Un indicateur conjoncturel de mortalité: I'exemple de la France. In: Population (French Edition) 48,2: 347-368.

Sardon, Jean-Paul 1994a: A period measure of mortality. The example of France. In: Population: An English Selection 6: 131-150.

Sardon, Jean-Paul 1994b: Probabilities, frequencies and events. In: Population: An English Selection 6: 151-157.

Schoen, Robert 2004: Timing effects and the interpretation of period fertility. In: Demography 41,4: 801-819 [doi: 10.1353/dem.2004.0036].

Schoen, Robert 2006: Dynamic population models. Demographic Methods and Population Analysis 17. Dordrecht: Springer. 
Schoen, Robert; Canudas-Romo, Vladimir 2005: Changing mortality and average cohort life expectancy. In: Demographic Research 13,5: 117-142 [doi:10.4054/ DemRes.2005.13.5].

Sobotka, Tomáš; Lutz, Wolfgang 2010: Misleading policy messages derived from the period TFR: Should we stop using it? In: Comparative Population Studies - Zeitschrift für Bevölkerungswissenschaft 35,3: 637-664 [doi: 10.4232/10.CPoS-2010-15en].

Statistisches Bundesamt 2006: Generationensterbetafeln für Deutschland. Modellrechnungen für die Geburtsjahrgänge 1871-2004. Wiesbaden: Statistisches Bundesamt

Statistisches Bundesamt 2009: Bevölkerung Deutschlands bis 2060. 12. koordinierte Bevölkerungsvorausberechnung. Begleitmaterial zur Pressekonferenz am 18. November 2009 in Berlin. Wiesbaden: Statistisches Bundesamt.

van Imhoff, Evert 2001: On the impossibility of inferring cohort fertility measures from period fertility measures. In: Demographic Research 5,2: 23-64 [doi:10.4054/ DemRes.2001.5.2].

van Imhoff, Evert; Keilman, Nico 2000: On the quantum and tempo of fertility: comment. In: Population and Development Review 26,3: 549-553.

Wachter, Kenneth W. 2005: Tempo and its tribulations. In: Demographic Research 13,9: 201-222 [doi:10.4054/DemRes.2005.13.9].

Ward, Michae/ P.; Butz, William P. 1980: Completed fertility and its timing. In: Journal of Political Economy 88,5: 917-940.

Wilmoth, John R. 2005: On the relationship between period and cohort mortality. In: Demographic Research 13,11: 231-280 [doi:10.4054/DemRes.2005.13.11].

Winkler-Dworak, Maria; Engelhardt, Henriette 2004: On the quantum and tempo of first marriages in Austria, Germany, and Switzerland: changes in mean age and variance. In: Demographic Research 10,9: 231-263 [doi:10.4054/DemRes.2004.10.9].

Yamaguchi, Kazuo; Beppu, Motomi 2004: Survival probability indices of period total fertility rate. Paper presented at the Annual Meeting of the Population Association of America 2004. Boston.

Zeng, Yi; Land, Kenneth C. 2001: A sensitivity analysis of the Bongaarts-Feeney method for adjusting bias in observed period total fertility rates. In: Demography 38,1: 17-28 [doi: 10.1353/dem.2001.0010].

Zeng, Yi; Land, Kenneth C., 2002: Adjusting period tempo changes with an extension of Ryder's basic translation equation. In: Demography 39,2: 269-285 [doi: 10.1353/ dem.2002.0022].

A German translation of this reviewed and author's authorised original article is available under the title "Tempo-Effekte und ihre Bedeutung für die demografische Analyse", DOI 10.4232/10. CPOS-2010-11de or URN urn:nbn:de:bib-cpos-2010-11de9, at http://www.comparativepopulationstudies.de.

Dr. Marc Luy $(\bowtie)$. Vienna Institute of Demography of the Austrian Academy of Sciences, Wittgenstein Centre for Demography and Global Human Capital, A-1040 Vienna, Austria. E-Mail: mail@marcluy.eu

URL: http://www.marcluy.eu 


\section{Comparative Population Studies - Zeitschrift für Bevölkerungswissenschaft}

www.comparativepopulationstudies.de

ISSN: 1869-8980 (Print) - 1869-8999 (Internet)

Published by / Herausgegeben von

Prof. Dr. Norbert F. Schneider

Layout and print: Federal Institute for Population Research, Wiesbaden (Germany)

Managing Editor / Redaktion

Frank Swiaczny

\section{Copy Editor / Schlussredaktion}

Dr. Evelyn Grünheid

\section{Scientific Advisory Board / Wissenschaftlicher Beirat}

Jürgen Dorbritz (Wiesbaden)

Paul Gans (Mannheim)

Johannes Huinink (Bremen)

Marc Luy (Wien)

Clara H. Mulder (Groningen)

Notburga Ott (Bochum)

Peter Preisendörfer (Mainz)

\section{Board of Reviewers / Gutachterbeirat}

Martin Abraham (Erlangen)

Laura Bernardi (Lausanne)

Hansjörg Bucher (Bonn)

Claudia Diehl (Göttingen)

Andreas Diekmann (Zürich)

Gabriele Doblhammer-Reiter (Rostock)

Henriette Engelhardt-Wölfler (Bamberg)

E.-Jürgen Flöthmann (Bielefeld)

Alexia Fürnkranz-Prskawetz (Wien)

Beat Fux (Zürich)

Joshua Goldstein (Rostock)

Karsten Hank (Mannheim)

Sonja Haug (Regensburg)

Franz-Josef Kemper (Berlin)

Michaela Kreyenfeld (Rostock)

Aart C. Liefbroer (Den Haag)

Kurt Lüscher (Konstanz)

Dimiter Philipov (Wien)

Tomáš Sobotka (Wien)

Heike Trappe (Rostock) 